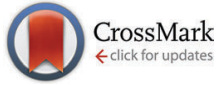

Cite this: Phys. Chem. Chem. Phys., 2015, 17, 21533

Received 3rd June 2015 Accepted 16th July 2015

DOI: $10.1039 / c 5 c p 03204 k$

www.rsc.org/pccp

\title{
Density functional theory calculations of the hydrazine decomposition mechanism on the planar and stepped $\mathrm{Cu}(111)$ surfaces
}

\begin{abstract}
Saeedeh S. Tafreshi, ${ }^{a}$ Alberto Roldan ${ }^{\mathrm{ab}}$ and Nora H. de Leeuw ${ }^{\star a b}$
We have investigated the adsorption of hydrazine $\left(\mathrm{N}_{2} \mathrm{H}_{4}\right)$ and its reactivity on terraces and steps of $\mathrm{Cu}(111)$ surfaces by first-principles calculations in order to gain insight into the hydrazine decomposition mechanism. We have investigated different possibilities for the $\mathrm{N}-\mathrm{N}$ and $\mathrm{N}-\mathrm{H}$ bond cleavage for any intermediate states by analysing the reaction and barrier energies of each elementary step. We have found that hydrazine dehydrogenation via $\mathrm{N}-\mathrm{H}$ bond scission is neither energetically nor kinetically favourable on the flat and stepped surfaces, but hydrazine prefers to form $\mathrm{NH}_{2}$ via $\mathrm{N}-\mathrm{N}$ bond decoupling on the $\mathrm{Cu}(111)$ with an activation energy below $1 \mathrm{eV}$. The $\mathrm{NH}_{2}$ molecule reacts fairly easily with co-adsorbed $\mathrm{NH}_{2}$ to form $\mathrm{NH}_{3}$ as well as with $\mathrm{N}_{2} \mathrm{H}_{x}(x=1-4)$ by abstracting hydrogen to produce $\mathrm{NH}_{3}$ and $\mathrm{N}_{2}$ molecules on both the flat and stepped surfaces. We also found that all intermediates except $\mathrm{NNH}$ prefer $\mathrm{N}-\mathrm{N}$ bond breaking as the most likely dissociation pathway, where the amide and imide intermediates produced can be hydrogenated to form $\mathrm{NH}_{3}$ in the presence of hydrogen. $\mathrm{NNH}$ is the only intermediate, which prefers to dissociate via a highly exothermic $\mathrm{N}-\mathrm{H}$ bond breaking process to produce an $\mathrm{N}_{2}$ molecule after overcoming a small barrier energy. We also studied the production of $\mathrm{H}_{2}$ by recombination of hydrogen ad-atoms which, considering the activation energies, is particularly favoured under conditions of moderate temperatures. Our results agree well with experiments suggesting that $\mathrm{N}_{2} \mathrm{H}_{4}$ adsorbs dissociatively on copper above 300 K leading to $\mathrm{N}_{2}, \mathrm{NH}_{3}$ and $\mathrm{H}_{2}$. In general, the lower coordination of the steps is found to lead to higher reactivity than on the flat $\mathrm{Cu}(111)$ surface. Furthermore, the calculations show that the influence of step edge atoms is very different for the intra- and intermolecular dehydrogenation mechanisms. They also increase the barrier of $\mathrm{N}-\mathrm{N}$ decoupling of all the existing species in the reaction.
\end{abstract}

\section{Introduction}

Hydrogen has received much attention over the last few decades as an energy resource, ${ }^{1,2}$ for instance, in the proton exchange membrane (PEM) fuel cells which are some of the new carbonfree technologies for power generators. However, finding materials with a high storage capacity of hydrogen at room temperature is difficult and much effort is spent on developing new materials or employing organic and inorganic compounds for onboard hydrogen generation. Hydrazine $\left(\mathrm{N}_{2} \mathrm{H}_{4}\right)$ with a hydrogen content of $12.5 \mathrm{wt} \%$ is a good hydrogen source for PEM fuel cells and since it is liquid at temperatures ranging from $2{ }^{\circ} \mathrm{C}$ to $114{ }^{\circ} \mathrm{C}$, it is ideal for portable applications, for example for its current use in space vehicles or satellites. ${ }^{3-5}$ Although hydrazine is a toxic substance, its decomposition products, $\mathrm{N}_{2}, \mathrm{H}_{2}$ and $\mathrm{NH}_{3}$, are

\footnotetext{
${ }^{a}$ Department of Chemistry, University College London, 20 Gordon Street, London, WC1H OAJ, UK

${ }^{b}$ School of Chemistry, Cardiff University, Main Building, Park Place, Cardiff, CF10 3AT, UK. E-mail: DeLeeuwN@cardiff.ac.uk; Tel: +44 (0)2920870658
}

non-poisonous and carbon-free. ${ }^{3}$ Its decomposition over catalysts at room temperature is exothermic without the need for external energy. Hydrazine is also used in a monopropellant thruster to control and adjust the orbits and altitudes of spacecrafts and satellites, ${ }^{4,6}$ which is based on the production of larger volumes of $\mathrm{N}_{2}, \mathrm{H}_{2}$ and $\mathrm{NH}_{3}$ gases from the decomposition of a relatively small volume of liquid hydrazine. The most important catalyst used for this reaction is $\operatorname{Ir} / \mathrm{Al}_{2} \mathrm{O}_{3}$ with a high loading of iridium (20-40\%). ${ }^{4,6-8}$ However, due to the high price and limited resources of iridium, scientists are seeking to develop new, cheaper, active and readily available alternative catalysts for $\mathrm{N}_{2} \mathrm{H}_{4}$ decomposition.

We aim to investigate at the molecular level the catalytic activity of $\mathrm{Cu}$ towards $\mathrm{N}_{2} \mathrm{H}_{4}$ decomposition to understand the thermodynamics and kinetics of the elementary steps, and to evaluate if copper-based catalysts, which are much cheaper than iridium, could be used for hydrazine decomposition. Experimental studies have revealed that adsorption of $\mathrm{N}_{2} \mathrm{H}_{4}$ on copper at relatively low temperatures is likely to be reversible and nondissociative up to $\sim 300 \mathrm{~K}$, above which hydrazine decomposes 
and generates the gaseous products $\mathrm{NH}_{3}, \mathrm{~N}_{2}$ and $\mathrm{H}_{2} \cdot{ }^{9,10}$ There are two typical reactions for hydrazine decomposition;

$$
\mathrm{N}_{2} \mathrm{H}_{4} \rightarrow \mathrm{N}_{2}+2 \mathrm{H}_{2}
$$

and

$$
3 \mathrm{~N}_{2} \mathrm{H}_{4} \rightarrow 4 \mathrm{NH}_{3}+\mathrm{N}_{2}
$$

The competition between the two decomposition reactions is influenced by the catalyst and the reaction conditions. A few comprehensive computational studies have been performed on the mechanism of hydrazine decomposition on transition metal surfaces, e.g. the density functional theory (DFT) study of hydrazine decomposition on the $\operatorname{Ir}(111)$ surface,${ }^{11}$ which showed that $\mathrm{N}-\mathrm{N}$ bond cleavage of hydrazine is more easily accomplished than that of the $\mathrm{N}-\mathrm{H}$ bond, and the $\mathrm{NH}_{2}$ radicals can abstract hydrogen atoms one by one from $\mathrm{N}_{2} \mathrm{H}_{4}$ resulting in the formation of $\mathrm{N}_{2}$ and $\mathrm{NH}_{3}$ molecules. On $\mathrm{Fe}(211),{ }^{12}$ the dehydrogenation and nitrogen decoupling are competitive routes, with $\mathrm{NH}_{2}$ and $\mathrm{N}$ being the dominant surface intermediates at mild temperatures, leading to gas-phase $\mathrm{N}_{2}$ and $\mathrm{NH}_{3}$ at higher temperatures. A DFT study of the dissociative adsorption of $\mathrm{N}_{2} \mathrm{H}_{4}$, by breaking of the hydrazine $\mathrm{N}-\mathrm{N}$ bond, on low-index planar copper surfaces with and without $\mathrm{Cu}$ adatoms, showed that dissociative adsorption is thermodynamically strongly favoured over molecular sorption. ${ }^{13}$ In this study, we have used improved DFT methodology, including long range interaction corrections to model more accurately the van der Waals forces, to analyse the thermodynamics and kinetics of the complete dissociation reaction.

Besides the more stable perfect and planar surfaces, defects and steps are common surface features. Previous experimental and theoretical results have suggested that low-coordinated sites show higher catalytic activity and can influence the overall surface chemistry. ${ }^{14-20}$ Dahl et al. ${ }^{21}$ showed that the energy barrier for $\mathrm{N}_{2}$ dissociation is more than $1 \mathrm{eV}$ lower on the $\mathrm{Ru}(0001)$ step edge than on the terraces. On the same surface, Zambelli et al. ${ }^{22}$ have reported that the step edges are the active sites for NO dissociation. Xu and Mavrikakis showed that the tensile strain at steps substantially facilitates the $\mathrm{O}_{2}$ activation on gold surfaces, ${ }^{23}$ although the effect of steps on $\mathrm{O}_{2}$ dissociation on $\mathrm{Cu}$ surfaces is not expected to be as pronounced as in other gasmetal systems. ${ }^{24}$ The results for CO dissociation on the Ni surface indicate that the energy barriers for CO dissociation strongly favour reactions occurring near surface steps. ${ }^{25} \mathrm{Fu}$ and Somorjai ${ }^{26}$ were able to provide evidence of the enhanced interaction of $\mathrm{CO}_{2}$ on $\mathrm{Cu}$ steps, which results in the sensitivity of the methanol synthesis process to copper surface structures. Some studies have shown that the effect of step edge atoms is very different for the different reaction pathways. For example, Vang et al. in their study on ethylene dissociation on flat and stepped $\mathrm{Ni}(111)$ found that on the steps the barrier for $\mathrm{C}-\mathrm{C}$ bond breaking is lowered significantly more than the barrier for dehydrogenation.

Following our investigation of the adsorption of molecular hydrazine on realistic Cu surfaces, ${ }^{27-29}$ here we have carried out density functional theory calculations including dispersive interactions, ${ }^{30,31}$ to characterize the most favourable adsorption sites, geometries and energies of the $\mathrm{N}_{2} \mathrm{H}_{4}$ decomposition intermediates. We have suggested and analysed three different decomposition mechanisms, including dehydrogenation via intra- and intermolecular pathways and $\mathrm{N}-\mathrm{N}$ bond cleavage, on both flat and stepped $\mathrm{Cu}(111)$ surfaces.

\section{Computational methods}

We have carried out electronic structure calculations using DFT as implemented in the Vienna $\mathrm{Ab}$ initio Simulation Package (VASP). ${ }^{32-35}$ The total energy calculations have been performed using the Perdew-Burke-Ernzerhof $(\mathrm{PBE})^{36}$ form of the generalized gradient approximation (GGA), whereas the projector augmented wave (PAW) method has been used to consider the effect of the inner cores on the valence density. ${ }^{37,38}$ To improve the description of the long-range interaction, and following our previous work on the $\mathrm{Cu}$-hydrazine system, ${ }^{27}$ we have employed the DFT-D2 method of Grimme as implemented in VASP, ${ }^{31}$ which has been shown to improve accuracy on several systems, e.g. ref. 27, 39 and 40. We have used the standard global scaling factor for the PBE functional within a damping function to avoid near singularities at small distances. We have also tested the DFT-D3 method to evaluate its effects on the adsorption energies compared to the DFT-D2 calculations. In line with Almora-Barrios et al., ${ }^{41}$ we found that the use of DFT-D3 led to larger binding energies, but also a more pronounced deviation from experimental values of the $\mathrm{Cu}$ lattice parameter and cohesive energy compared with those obtained by DFT-D2. ${ }^{42}$ In this paper, we consider the energy differences between competing reactions to identify the preferred reaction mechanisms and pathways relative to each other, and as such DFT-D2 represents a sufficiently accurate model of the system to identify the reaction trends for hydrazine dissociation on the $\mathrm{Cu}$ surface.

Plane wave basis sets were used with an energy cut-off of $600 \mathrm{eV}$, which gave bulk energies converged to within $0.001 \mathrm{eV}$ per atom. A $5 \times 5 \times 1$ and $3 \times 5 \times 1$ Monkhorst-Pack grid ${ }^{43}$ of $k$ points was used to sample the Brillouin zone for flat and stepped surfaces respectively. Spin polarization has been tested in a few cases but was found to be irrelevant.

The flat and stepped slabs were modelled with a $2 \times 2$ and $3 \times 2$ supercell from the full unit cell, $p(4 \times 4)$ and $p(6 \times 4)$, with $20 \AA$ of vacuum between slabs in the $z$-direction where $\mathrm{Cu}-\mathrm{Cu}$ distances were originally taken from the fully optimised bulk geometry. The adsorbate and the top three layers out of four and five layers of the flat and stepped slabs, respectively, were allowed to relax during structural optimisation, in line with previous studies. ${ }^{44,45}$ Different slab thicknesses were tested until convergence was achieved within $0.01 \mathrm{eV}$ per cell.

We have calculated the adsorption energies of the intermediates from the hydrazine decomposition process relative to the hydrazine molecule in the gas-phase:

$$
\begin{aligned}
E_{\mathrm{ads}}\left(\mathrm{N}_{y} \mathrm{H}_{x}\right)= & \left(E_{\mathrm{N}_{y} \mathrm{H}_{x}}^{\text {surf }}+(4-x) E_{\mathrm{H}}^{\text {surf }}+(2-y) E_{\mathrm{N}}^{\text {surf }}\right) \\
& -\left(((4-x)+(2-y)+1) E^{\text {surf }}+E_{\mathrm{N}_{2} \mathrm{H}_{4}}^{\text {gas }}\right)
\end{aligned}
$$


Where $E_{\mathrm{N}_{y} \mathrm{H}_{x}}^{\text {surf }}$ is the total energy of the $\mathrm{N}_{y} \mathrm{H}_{x}$ species adsorbed on a relaxed surface and $E_{\mathrm{H}}^{\text {surf }}$ and $E_{\mathrm{N}}^{\text {surf }}$ are the energies of an isolated $\mathrm{H}$ - and $\mathrm{N}$-atom adsorbed somewhere else on the relaxed surface, at a non-interactive distance. $E^{\text {surf }}$ and $E_{\mathrm{N}_{2} \mathrm{H}_{4}}^{\mathrm{gas}}$ are the energies of the naked surface and isolated gas-phase hydrazine respectively. Within this definition, a negative $E_{\text {ads }}$ value means a release of energy during adsorption. A combination of two varieties of the nudged elastic band (NEB) method ${ }^{46,47}$ and the improved dimer method (IDM) ${ }^{48}$ was used to identify transition state (TS) structures, which we verified by a single imaginary frequency associated with the reaction coordinate. The reaction energy $\left(E_{\mathrm{r}}\right)$ was obtained from the difference in energy between final and initial states and a negative $E_{\mathrm{r}}$ hence indicates an exothermic process. The forward and reverse activation barriers $\left(E_{\mathrm{a}}\right)$ were defined as the energy difference between the TS and the initial state or the final state, respectively.

\section{Results}

We have first created the perfect $\mathrm{Cu}(111)$ surface, which is the close-packed plane of the fcc structure (Fig. 1a) and is the most stable copper surface. ${ }^{49}$ The surface $\mathrm{Cu}$ atoms are arranged in a hexagonal lattice with a separation of $2.52 \AA$ between nearest neighbour atoms. The stepped $\mathrm{Cu}(111)$ surface has been studied to investigate the presence of an extended edge of low-coordinated atoms on the $\mathrm{N}_{2} \mathrm{H}_{4}$ dissociation behaviour (shown in Fig. 1b). Each unit cell in the stepped slab was offset by one atomic layer with respect to the next cell. ${ }^{50-52}$

The three major conformations of hydrazine in the gasphase are gauche, trans and eclipsed (Fig. 2), where the gauche conformer is the lowest-energy structure. The trans and eclipsed conformations are 0.13 and $0.36 \mathrm{eV}$ higher in energy, respectively, than the gauche conformation. We have identified the strongest adsorption geometries by placing the different intermediates at a variety of positions on the planar and stepped $\mathrm{Cu}(111)$ surfaces. Adsorption energies and structural parameters for various intermediate species in their most stable configurations on the flat and stepped $\mathrm{Cu}(111)$ are presented in Table 1 and Fig. 3 . We note that because of the lower coordination of the stepped surface atoms, all intermediates are more stable on the step than on the terrace sites.

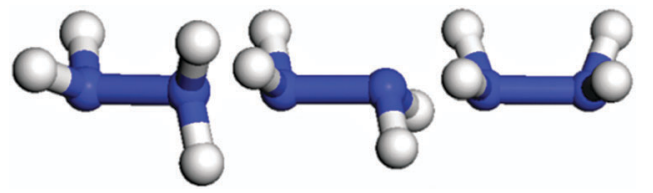

Fig. 2 Representation of the $\mathrm{N}_{2} \mathrm{H}_{4}$ conformations, from left to right: gauche, trans and eclipsed.

\subsection{Adsorption on the planar and stepped $\mathrm{Cu}(111)$}

$\mathbf{N}_{2} \mathbf{H}_{4}$. We placed different $\mathrm{N}_{2} \mathrm{H}_{4}$ conformers (Fig. 2) in a number of non-equivalent initial configurations on the planar and stepped $\mathrm{Cu}(111)$ surface in order to identify the mode of strongest adsorption. The preferred $\mathrm{N}_{2} \mathrm{H}_{4}$ adsorption structures on the flat and stepped $\mathrm{Cu}(111)$ surfaces are in the gauche conformation, releasing an $E_{\text {ads }}$ of 0.98 and $1.53 \mathrm{eV} / \mathrm{N}_{2} \mathrm{H}_{4}$ respectively. While it binds through both nitrogen atoms to the flat surface, $\eta^{2}(\mathrm{~N}, \mathrm{~N})$, with $\mathrm{Cu}-\mathrm{N}$ distances of $2.178 \AA$, it prefers to bridge to the copper step edge atoms with shorter $\mathrm{Cu}-\mathrm{N}$ distances of 2.104 A. Hydrazine adsorbs almost parallel to both the flat and stepped surfaces, elongating the $\mathrm{N}-\mathrm{N}$ bond to 1.452 and $1.455 \AA$ respectively, compared to a length of $1.438 \AA$ in the gas-phase. These configurations are a result of $\mathrm{N}-\mathrm{N}$ bond rotation from gauche toward the eclipsed conformer with a torsional angle of $39.6^{\circ}$ and $34.6^{\circ}$ on the flat and stepped surfaces respectively.

$\mathbf{N}_{2} \mathbf{H}_{3}$. As the first product of dehydrogenation, the most stable adsorption structure for the $\mathrm{N}_{2} \mathrm{H}_{3}$ conformer is the $\mathrm{NHNH}_{2}$ structure, which has different binding geometries on the flat versus the stepped $\mathrm{Cu}(111)$ surfaces: on the terrace, it prefers the hollow site with the NH-end closer to the surface, bridging two surface $\mathrm{Cu}$ atoms with a $\mathrm{Cu}-\mathrm{N}$ bond length of $\sim 2.0 \AA$, whereas the $\mathrm{NH}_{2}$ part has a $\mathrm{Cu}-\mathrm{N}$ bond length of $2.070 \AA$ A. On the step, it binds on the edge atoms with its $\mathrm{NH}$-end inclined to the lower terrace, with a Cu-N distance of $2.078 \AA$. The N-N bond on the step edge elongates to $1.462 \AA$ compared to $1.455 \AA$ on the terrace. While the energy of $\mathrm{N}_{2} \mathrm{H}_{3}$ adsorption on the terrace is $-0.85 \mathrm{eV}$ relative to gas-phase hydrazine, it adsorbs more strongly to the step edge by $0.36 \mathrm{eV}$.

$\mathbf{N}_{2} \mathbf{H}_{2}$. The next intermediate is $\mathrm{N}_{2} \mathrm{H}_{2}$, which has two different conformers: $\mathrm{NHNH}$, with one hydrogen atom at each nitrogen or $\mathrm{NNH}_{2}$, where both hydrogen atoms are located on the same nitrogen. While the latter adsorbs perpendicularly on the

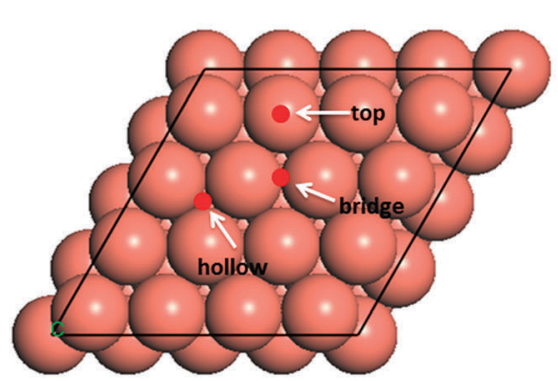

(a)

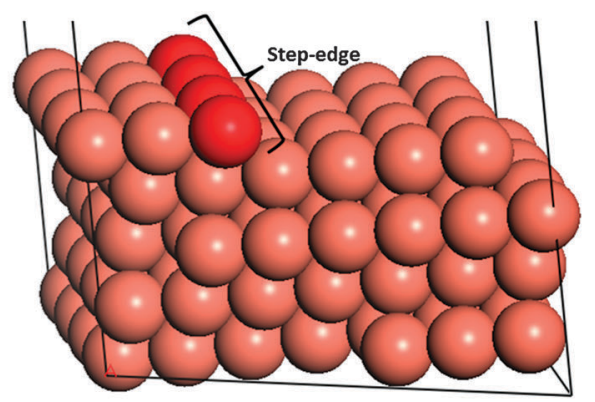

(b)

Fig. 1 The simulation cells and surface geometry of different sites used in the calculations of (a) perfect (top view) and (b) stepped (side view) surfaces. Note that low-coordinated atoms in the stepped surface are shaded darker. 
Table 1 Adsorption energies $\left(E_{\text {ads }}\right)$ and average geometric parameters of the most favourable adsorption structures of different $\mathrm{N}_{2} \mathrm{H}_{4}$ decomposition intermediates on the flat and stepped $\mathrm{Cu}(111)$ surface. Adsorption energies are relative to the gas-phase hydrazine; bold numbers show the adsorption energies relative to the species in their gas-phase: $\mathrm{NH}_{3}, \mathrm{~N}_{2}$ and $\mathrm{H}_{2}$

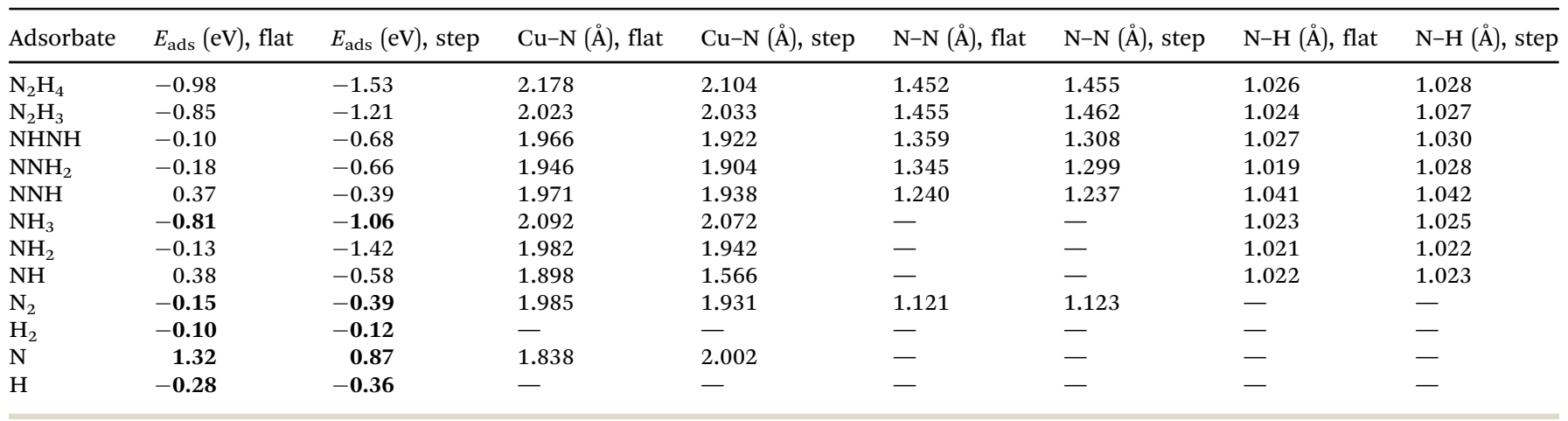
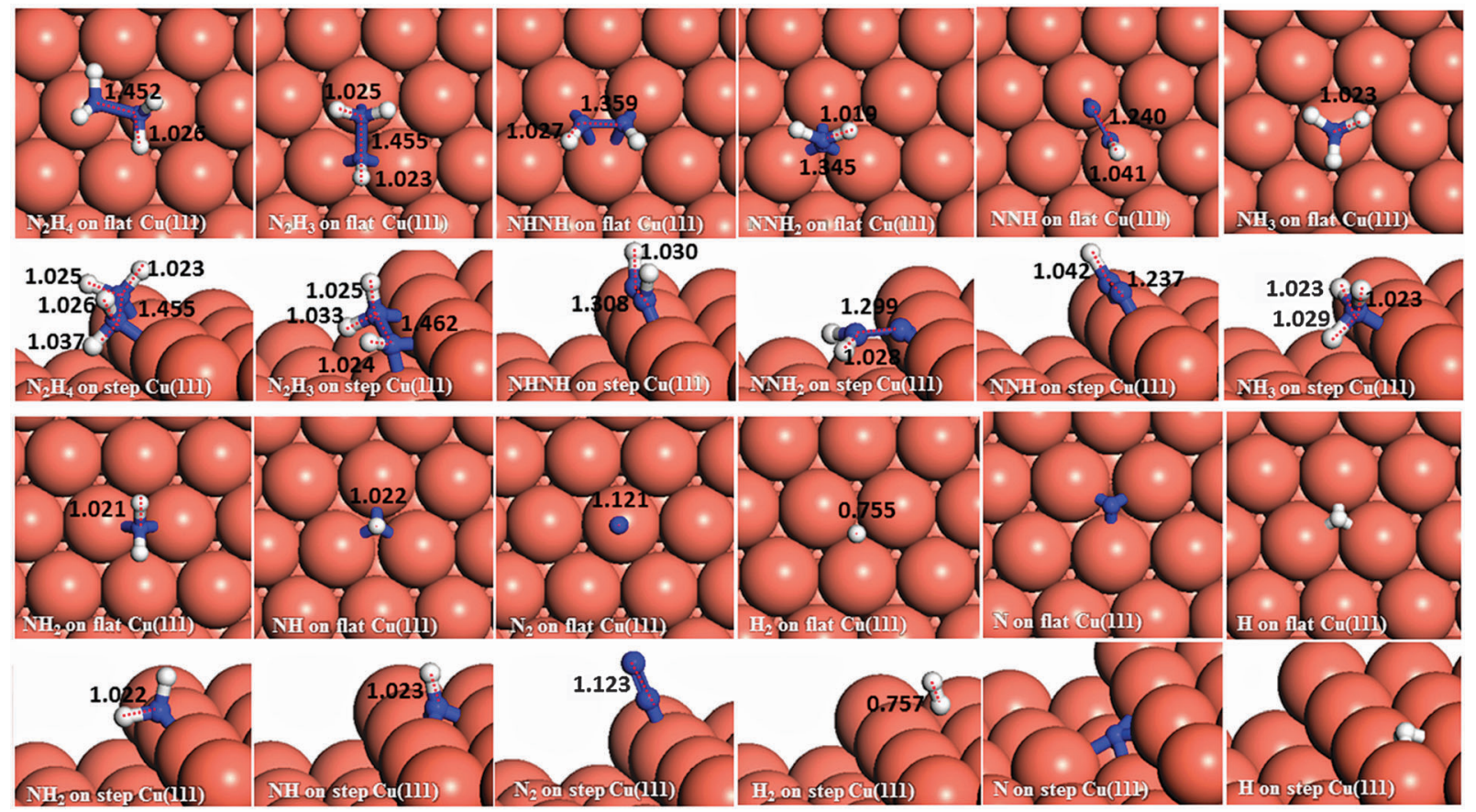

Fig. 3 Surface geometries of the preferred adsorption configurations of the various intermediates on the flat (top-view) and stepped (side-view) Cu(111) surfaces with their $\mathrm{N}-\mathrm{N}$ and $\mathrm{N}-\mathrm{H}$ bond distances in $\AA$.

terrace with the lower $\mathrm{N}$ atom in a three-fold hollow site $\left(E_{\text {ads }}=\right.$ $-0.18 \mathrm{eV}$ ), it prefers to bridge through the $\mathrm{N}$ on the step edge, lying parallel to the lower terrace with a larger adsorption energy of $-0.66 \mathrm{eV}$. The adsorption of the NHNH structure on the terrace releases only $0.10 \mathrm{eV}$ when it adsorbs through both nitrogen atoms in an hcp site parallel to the surface. NHNH bridges on the $\mathrm{Cu}$ step edges more strongly, releasing an energy of $0.68 \mathrm{eV}$.

$\mathbf{N}_{2} \mathbf{H}$. The adsorption geometries of $\mathrm{N}_{2} \mathrm{H}$ are identical on both terrace and step surfaces, adsorbing on a bridge site through both nitrogen atoms parallel to the surface. While this process is endothermic $\left(E_{\mathrm{ads}}=0.37 \mathrm{eV}\right)$ on the terrace, the adsorption on the step edge is exothermic, releasing an energy of $0.39 \mathrm{eV}$. The $\mathrm{N}-\mathrm{N}$ bond lengths on terrace and step edge are 1.240 and $1.237 \AA$ respectively, i.e. elongated compared to $1.150 \AA$ of the $\mathrm{N}_{2} \mathrm{H}$ molecule in the gas-phase. ${ }^{53}$
$\mathbf{N}_{2}$. We investigated the $\mathrm{N}_{2}$ molecule adsorption at different sites on the surface and found that $\mathrm{N}_{2}$ adsorbs on a top site on both the terrace or the step edge, with the molecule's axis perpendicular to the surface at $\mathrm{Cu}-\mathrm{N}$ distances of 1.985 and $1.931 \AA$ respectively. The $\mathrm{N}_{2}$ adsorption energy with respect to gas-phase nitrogen is -0.15 and $-0.39 \mathrm{eV}$ on the flat and stepped surfaces respectively. It shows that nitrogen adsorption on the $\mathrm{Cu}$ surfaces is weak and it could easily desorb by increasing the temperature. The $\mathrm{N}-\mathrm{N}$ bond length is 1.121 and $1.123 \AA$ on the terrace and step edge respectively (an experimental bond length of $1.098 \AA$ in the gas-phase ${ }^{54}$ ). In other sites, $\mathrm{N}_{2}$ interacts more weakly and the molecule moves away to $\sim 3 \AA$ from the surface.

$\mathbf{N}$. The nitrogen atom adsorbs on a three-fold hollow site on the terrace and on a four-fold site at the foot of the step edge, 
both endothermically requiring 1.32 and $0.87 \mathrm{eV}$ on the terrace and step edge, respectively, relative to gas-phase $\mathrm{N}_{2}$. This preference by $\mathrm{N}$ for a three-fold adsorption site on $\mathrm{Cu}(111)$ was also found in previous work. ${ }^{55}$

$\mathbf{N H}_{3}$. The adsorption geometry of ammonia is identical on both the flat and stepped $\mathrm{Cu}$ surfaces with a preference for a top site, with $\mathrm{Cu}-\mathrm{N}$ bond lengths of 2.092 and $2.072 \AA$ on the flat and stepped surfaces respectively. Theoretical studies have shown that strong electrostatic contributions ${ }^{56}$ and the Pauli repulsion of the lone-pair orbital of $\mathrm{NH}_{3}$ by the copper 3d electrons ${ }^{57}$ direct $\mathrm{NH}_{3}$ towards one-fold adsorption on the copper surfaces. The $\mathrm{NH}_{3}$ adsorption is exothermic with energies of -0.81 and $-1.06 \mathrm{eV}$ relative to gas-phase $\mathrm{NH}_{3}$ on the terrace and step edge, respectively. These results show that the ammonia molecule adsorbs relatively strongly to the $\mathrm{Cu}$ surface and its desorption would be endothermic.

$\mathbf{N H}_{2}$. The presence of low-coordinated $\mathrm{Cu}$ atoms stabilizes the $\mathrm{NH}_{2}$ intermediates more than any other species, by increasing the $\mathrm{NH}_{2}$ adsorption energy from -0.13 to $-1.42 \mathrm{eV}$, while the adsorption geometry remains the same on both the terrace and step edge with $\mathrm{NH}_{2}$ bridging between $\mathrm{Cu}$ surface atoms. The $\mathrm{Cu}-\mathrm{N}$ bond and $\mathrm{N}-\mathrm{H}$ bond lengths are $1.982 \AA$ and $1.021 \AA$ on the terrace and $1.942 \AA$ and $1.022 \AA$ on the step edge, which are slightly shorter than the experimentally reported $\mathrm{N}-\mathrm{H}$ bond in the gas-phase $(1.024 \AA) .{ }^{58}$

NH. The adsorption of imide is endothermic by $0.38 \mathrm{eV}$ on the flat $\mathrm{Cu}(111)$ surface, while on the stepped $\mathrm{Cu}(111)$ surface it is exothermic by $0.58 \mathrm{eV}$. The adsorption geometry for $\mathrm{NH}$ is identical on both the terrace and step edge, where it adsorbs on a three-fold hollow site, with a Cu-N bond length of $1.566 \AA$ on the step edge compared to $1.898 \AA$ on the flat surface.

$\mathbf{H}_{2}$. The hydrogen molecule releases an energy of $0.10 \mathrm{eV}$ relative to gas-phase hydrogen, when it is perpendicularly adsorbed on the fcc site of the terrace, with an $\mathrm{H}-\mathrm{H}$ bond length of $0.755 \AA$ (an experimental bond length of $0.741 \AA$ in the gas-phase $\mathrm{s}^{54,58}$ ). The adsorption on the step edge does not change the $\mathrm{H}_{2}$ geometry on the $\mathrm{Cu}(111)$ surface, but makes it slightly more exothermic $\left(E_{\mathrm{ads}}=\right.$ $-0.12 \mathrm{eV}$ ) relative to gas-phase hydrogen. As such, hydrogen is physisorbed to the $\mathrm{Cu}$ surfaces at a distance of $\sim 2.80 \AA$, indicating that it should easily desorb from the surface.

H. For the hydrogen atom, similar to the nitrogen atom, the three-fold hollow site is the preferred site at low coverage. The hydrogen adsorption on both the flat and stepped surfaces is exothermic relative to gas-phase hydrogen, by 0.28 and $0.36 \mathrm{eV}$, respectively.

\section{2 $\mathrm{N}_{2} \mathrm{H}_{x}(x=1-4)$ decomposition pathways on the planar and stepped $\mathrm{Cu}(111)$}

3.2.1 $\mathbf{N}_{2} \mathrm{H}_{4}$ dissociation and dehydrogenation. Table 2 summarizes the energetics of the different reaction pathways on both planar and stepped $\mathrm{Cu}(111)$ surfaces. We started from the most stable geometry of hydrazine, where hydrazine bridges through both nitrogen atoms to the $\mathrm{Cu}$ surface atoms. The pathways for hydrazine $\mathrm{N}-\mathrm{N}$ bond breaking on both flat and stepped surfaces, leading to $\mathrm{NH}_{2}$ intermediates, are shown in Fig. 4a. The reaction is exothermic $(0.87 \mathrm{eV})$ on the flat surface with an energy barrier of $0.86 \mathrm{eV}$. The presence of low-coordinated atoms in the step makes the $\mathrm{N}-\mathrm{N}$ bond breaking process more exothermic, releasing an energy of $1.66 \mathrm{eV}$, although the energy barrier is increased by $0.04 \mathrm{eV}$. This indicates that although a stepped surface favours the $\mathrm{N}-\mathrm{N}$ bond breaking thermodynamically, it does not modify the kinetics of the reaction.

Dehydrogenation of $\mathrm{N}_{2} \mathrm{H}_{4}$ was also investigated (Fig. 4b). The energy barrier for this path on the flat surface is $1.55 \mathrm{eV}$ and the process is endothermic by $0.31 \mathrm{eV}$. The activation energy on the stepped surface decreases to $1.11 \mathrm{eV}$, but the process becomes less favourable thermodynamically $\left(E_{\mathrm{r}}=0.74 \mathrm{eV}\right)$.

These results indicate that on $\mathrm{Cu}(111)$, with or without surface steps, the $\mathrm{N}-\mathrm{N}$ bond cleavage of hydrazine is energetically and kinetically preferred over its dehydrogenation, which is in line with a previous experimental study showing that $\mathrm{N}-\mathrm{H}$ bond breaking requires more energy than N-N breaking. ${ }^{59}$ From the charge density calculations in our previous work, ${ }^{27}$ which shows the induced charge density on the $\mathrm{Cu}(111)$ surface upon $\mathrm{N}_{2} \mathrm{H}_{4}$ adsorption, it can be observed that more charge is accumulated between the $\mathrm{N}$ and $\mathrm{H}$ atoms of hydrazine than between the two $\mathrm{N}$ atoms, which agrees well with these energetic results.

3.2.2 $\quad \mathbf{N}_{2} \mathrm{H}_{3}$ dissociation and dehydrogenation. The $\mathrm{N}_{2} \mathrm{H}_{3}$ decomposition may proceed by $\mathrm{N}-\mathrm{N}$ or $\mathrm{N}-\mathrm{H}$ breaking. Initially, transition and final states for the $\mathrm{N}-\mathrm{N}$ scission are represented in Fig. 5a leading to $\mathrm{NH}$ and $\mathrm{NH}_{2}$. While this process has an activation barrier of $1.06 \mathrm{eV}$ and the reaction is exothermic by $0.30 \mathrm{eV}$ on the flat surface, the barrier increases by $0.21 \mathrm{eV}$ but the reaction becomes more exothermic $(0.76 \mathrm{eV})$ on the stepped surface.

There are two distinct pathways for dehydrogenation of $\mathrm{N}_{2} \mathrm{H}_{3}$, respectively, shown in Fig. $5 \mathrm{~b}$ and c. The one leading to $\mathrm{NNH}_{2}$ and a $\mathrm{H}$ atom has a barrier and reaction energy of 1.53 and $0.74 \mathrm{eV}$, respectively, on the flat surface, and 1.77 and $0.75 \mathrm{eV}$ on the step. The alternative dehydrogenation pathway leads to NHNH and $\mathrm{H}$ as products. The barrier for this endothermic process $\left(E_{\mathrm{r}}=0.84 \mathrm{eV}\right)$ is $1.61 \mathrm{eV}$ on the flat surface, while the step decreases the barrier to $1.56 \mathrm{eV}$ although it is still endothermic $\left(E_{\mathrm{r}}=0.69 \mathrm{eV}\right)$.

Although $\mathrm{NHNH}$ and $\mathrm{NNH}_{2}$ are products of the dehydrogenation of $\mathrm{N}_{2} \mathrm{H}_{3}$ on the $\mathrm{Cu}(111)$ surface, the $\mathrm{N}-\mathrm{N}$ bond breaking of $\mathrm{N}_{2} \mathrm{H}_{3}$ is energetically more favourable. Our results indicate that low-coordinated atoms make the N-N decoupling of $\mathrm{N}_{2} \mathrm{H}_{3}$ more feasible thermodynamically, although they do not affect the kinetics.

3.2.3 $\quad \mathrm{N}_{2} \mathrm{H}_{2}$ dissociation and dehydrogenation. We have studied the processes of $\mathrm{N}-\mathrm{N}$ and $\mathrm{N}-\mathrm{H}$ breaking of two $\mathrm{N}_{2} \mathrm{H}_{2}$ conformations: $\mathrm{NNH}_{2}$ and $\mathrm{NHNH}$. The pathway for $\mathrm{N}-\mathrm{N}$ bond breaking of the $\mathrm{NNH}_{2}$ intermediate, yielding $\mathrm{NH}_{2}$ and $\mathrm{N}$, see Fig. 6a, has an activation barrier and a reaction energy of 1.42 and $+0.13 \mathrm{eV}$ respectively. When the stepped surface is considered the $\mathrm{N}-\mathrm{N}$ breaking barrier increases by $0.1 \mathrm{eV}$ and the process is $0.05 \mathrm{eV}$ more endothermic compared to the terrace. The dehydrogenation process of $\mathrm{NNH}_{2}$ leads to $\mathrm{NNH}$ and an $\mathrm{H}$ atom (Fig. 6b). For this process on the flat surface, the required energy is $1.35 \mathrm{eV}$ and the products are $0.58 \mathrm{eV}$ higher in energy than the reactants. On the stepped surface, the barrier energy 
Table 2 Calculated reaction $\left(E_{\mathrm{r}}\right)$ and barrier $\left(E_{\mathrm{a}}\right)$ energies for the forward and reverse reaction pathways considered. Note that $\left({ }^{\star}\right)$ indicates the adsorbed state. $E_{\mathrm{r}}$ values of the adsorption and desorption processes are the corresponding $E_{\text {ads }}$ values which for each species were calculated relative to the gas-phase

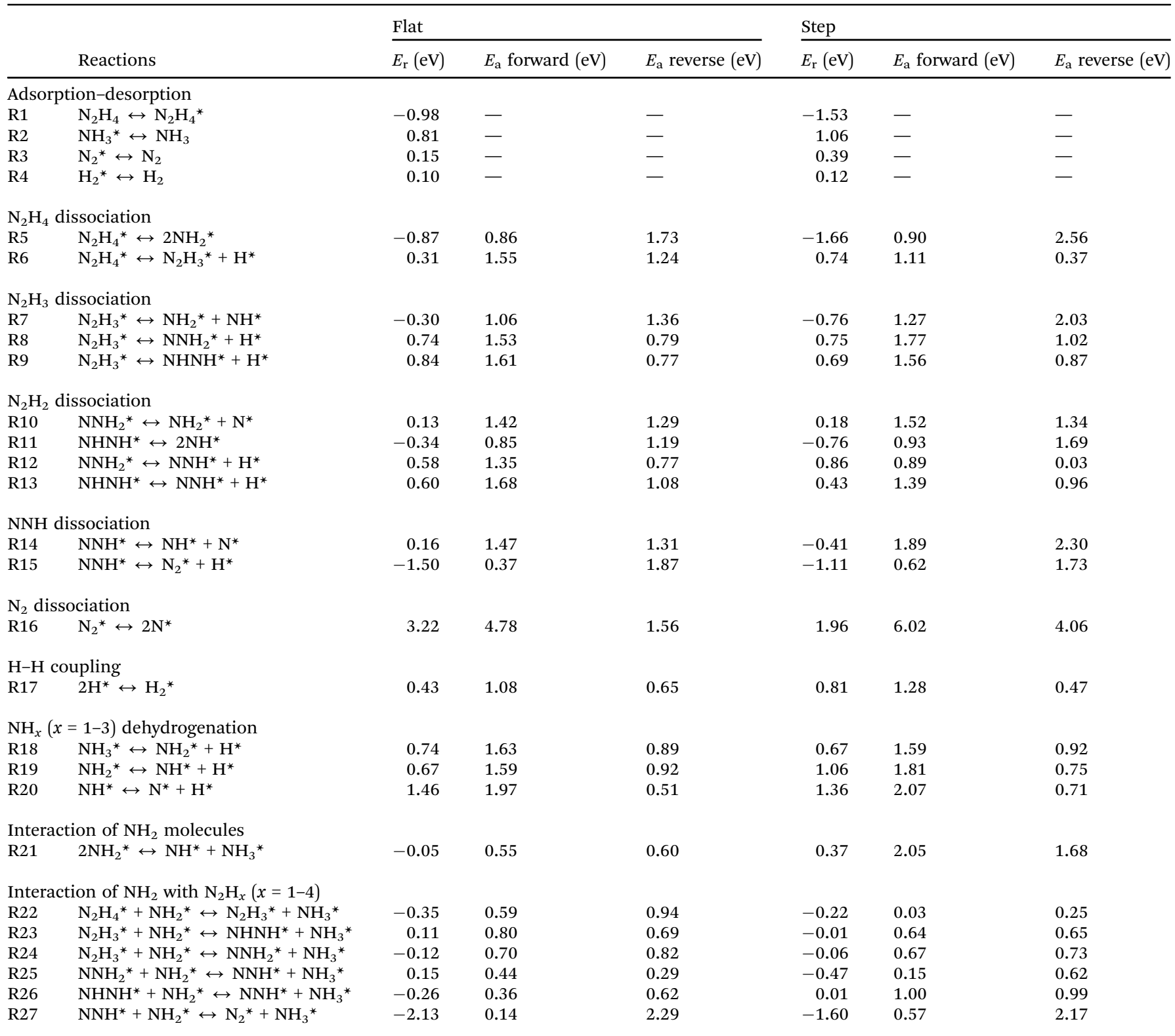

decreases to $0.89 \mathrm{eV}$ but the process is more endothermic by $0.28 \mathrm{eV}$.

As to $\mathrm{N}-\mathrm{N}$ bond breaking of $\mathrm{NHNH}$ (Fig. 7a), while the reaction barrier is $0.85 \mathrm{eV}$ and the reaction is exothermic by $-0.34 \mathrm{eV}$ on the flat surface, these values increase to 0.93 and $-0.76 \mathrm{eV}$, respectively, on the atomic step system. However, the dehydrogenation of $\mathrm{NHNH}$ resulting in $\mathrm{NNH}$ and an $\mathrm{H}$ species has a barrier of $1.68 \mathrm{eV}$ and is endothermic by $0.60 \mathrm{eV}$ on the flat surface (Fig. 7b). The lower coordination of the steps decreases both the barrier and the reaction energy to 1.39 and $0.43 \mathrm{eV}$ respectively. Thus, the production of $\mathrm{NH}$ molecules via $\mathrm{N}-\mathrm{N}$ bond breaking of $\mathrm{NHNH}$ is more favourable than other dissociation mechanisms of $\mathrm{N}_{2} \mathrm{H}_{2}$ from both thermodynamic and kinetic points of view.
3.2.4 NNH dissociation and dehydrogenation. Schematic representation of the NNH dissociation on the $\mathrm{Cu}(111)$ terrace is shown in Fig. 8a, where breaking the $\mathrm{N}-\mathrm{N}$ bond leads to $\mathrm{NH}$ and $\mathrm{N}$. The process has to overcome an energy barrier of $1.47 \mathrm{eV}$ and it is slightly endothermic $\left(E_{\mathrm{r}}=0.16 \mathrm{eV}\right)$. The step edge makes the process more favourable thermodynamically with an exothermic reaction energy of $-0.41 \mathrm{eV}$, but the energy barrier increases to $1.89 \mathrm{eV}$, making it therefore less feasible kinetically. The dehydrogenation reaction of $\mathrm{NNH}$, which completes the dehydrogenation process of $\mathrm{N}_{2} \mathrm{H}_{4}$, is represented in Fig. 8b. This reaction pathway has energy barriers of 0.37 and $0.62 \mathrm{eV}$ and is highly exothermic by $-1.50 \mathrm{eV}$ and $-1.11 \mathrm{eV}$ on the terrace and the step edge, respectively, which therefore becomes the most feasible intramolecular dehydrogenation reaction of any intermediate on the $\mathrm{Cu}(111)$ surface. 

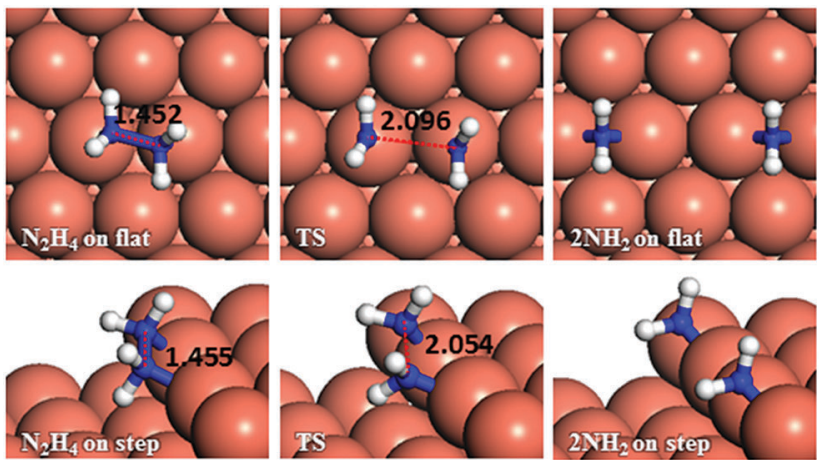

(a)
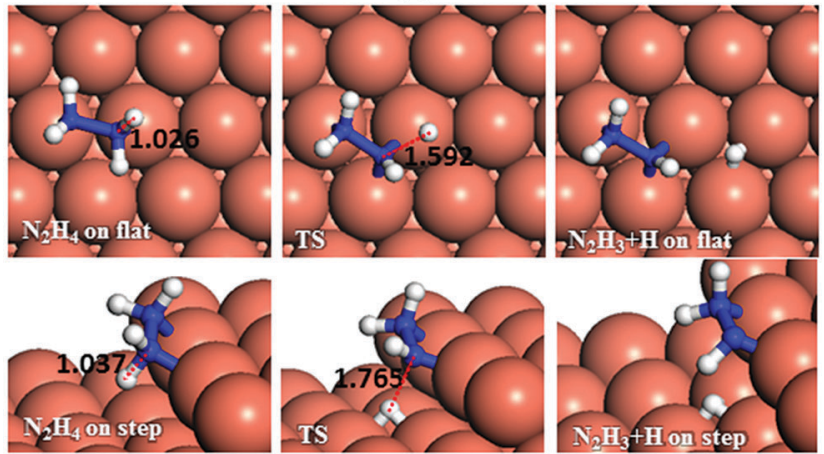

(b)

Fig. 4 Schematic representation of the initial, transition and final states for $\mathrm{N}_{2} \mathrm{H}_{4}$ dissociation pathways on the flat (top-view) and stepped (sideview) $\mathrm{Cu}(111)$ surfaces via (a) $\mathrm{N}-\mathrm{N}$, (b) $\mathrm{N}-\mathrm{H}$ breaking. Bond lengths are given in $\AA$.

3.2.5 $\mathbf{N}_{2}$ dissociation. We have also considered the reaction pathway for $\mathrm{N}-\mathrm{N}$ decoupling in the $\mathrm{N}_{2}$ molecule on $\mathrm{Cu}(111)$ surfaces (Fig. 9). As expected, due to the molecule's strong interatomic bond, the process is highly unaffordable with energy barriers of $4.78 \mathrm{eV}$ on the terrace and $6.02 \mathrm{eV}$ on the step edge. The process is also highly endothermic $\left(E_{\mathrm{r}}=3.22 \mathrm{eV}\right)$ on the terrace, although the step reduces the endothermic reaction energy to $1.96 \mathrm{eV}$.

\section{3 $\mathrm{NH}_{x}(x=1-3)$ dehydrogenation}

We have also investigated the consecutive dehydrogenation of ammonia, see Fig. 10a. The barrier and the endothermic reaction energy associated with the first $\mathrm{N}-\mathrm{H}$ bond breaking process are $1.63 \mathrm{eV}$ and $0.74 \mathrm{eV}$, respectively, on the flat surface, i.e. slightly higher than the barrier of $1.59 \mathrm{eV}$ and a reaction energy of $0.67 \mathrm{eV}$ on the step. The exothermic reverse (hydrogenation) reaction is more likely to happen with energy barriers of 0.89 and $0.92 \mathrm{eV}$ on the terrace and step respectively. The dehydrogenation of $\mathrm{NH}_{2}$ (Fig. 10b) and further dehydrogenation of $\mathrm{NH}$ (Fig. 10c) are also unlikely to succeed based on their associated high barrier energies, i.e. 1.59 and $1.97 \mathrm{eV}$ on the flat surface and 1.81 and 2.07 on the stepped surface, respectively. The DFT calculated barrier energies for the dehydrogenation of $\mathrm{NH}_{3}, \mathrm{NH}_{2}$ and $\mathrm{NH}$ to form $\mathrm{HCN}$ on $\mathrm{Pt}(111)$ are smaller than our results, i.e. $1.39,1.30$ and $1.40 \mathrm{eV}$ respectively, ${ }^{60}$ although not significantly.
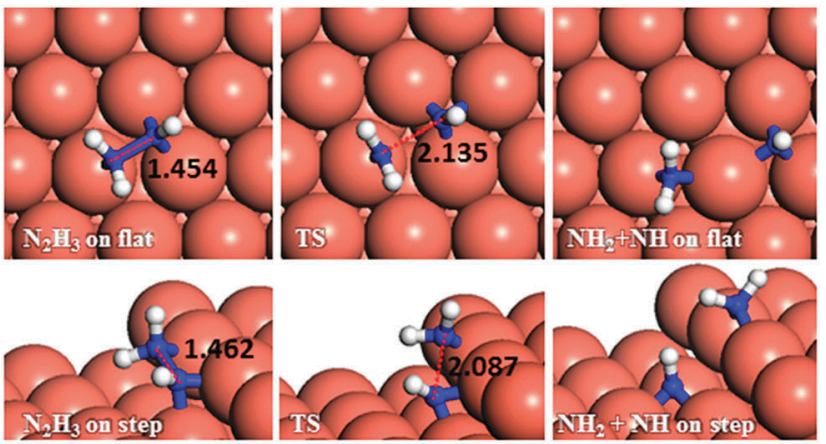

(a)
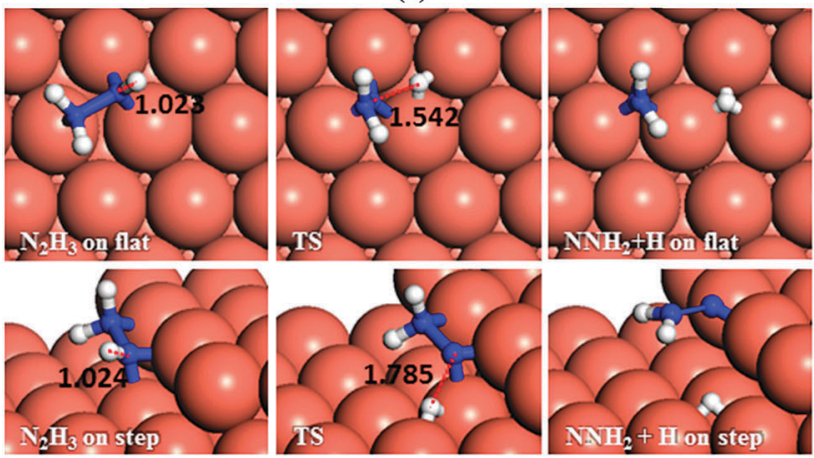

(b)
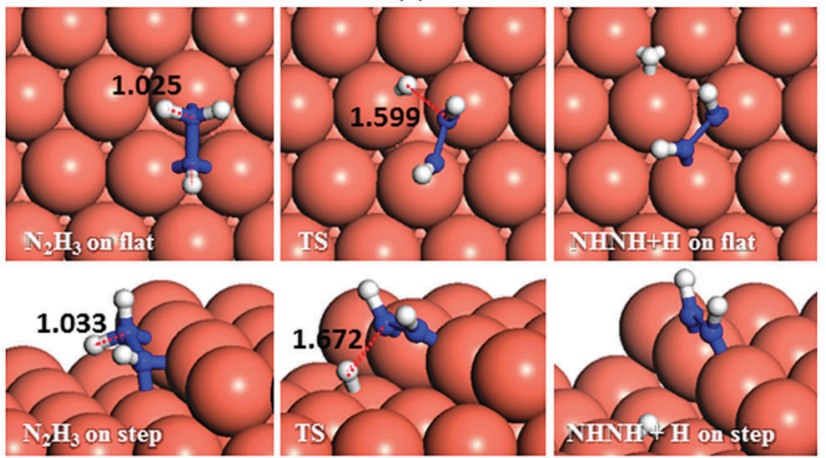

(c)

Fig. 5 Schematic representation of the initial, transition and final states for $\mathrm{N}_{2} \mathrm{H}_{3}$ dissociation pathways on the flat (top-view) and stepped (side-view) $\mathrm{Cu}(111)$ surfaces via (a) $\mathrm{N}-\mathrm{N}$, (b) and (c) $\mathrm{N}-\mathrm{H}$ breaking. Bond lengths are given in $\AA$.

The reverse process, hydrogenation of $\mathrm{NH}$ has activation energies of 0.92 and $0.75 \mathrm{eV}$ on the terrace and step, respectively. The hydrogenation of $\mathrm{N}$ is energetically favourable $\left(E_{\mathrm{r}}=-1.46\right.$ and $-1.36 \mathrm{eV}$ ) leading to $\mathrm{NH}$ via energy barriers of only 0.51 and $0.71 \mathrm{eV}$ on the flat and stepped surfaces, respectively. These energies show that the $\mathrm{Cu}$ surface could be a good catalyst for ammonia synthesis compared to the $\mathrm{Ru}(0001)$ surface, where the calculated barriers for hydrogenation of $\mathrm{N}, \mathrm{NH}$ and $\mathrm{NH}_{2}$ were found to be more than 1.2 and $1.1 \mathrm{eV}$ on terraces and steps, respectively. ${ }^{61,62}$

\subsection{H-H coupling}

We have also considered another secondary process, the pathways for $\mathrm{H}-\mathrm{H}$ coupling, see Fig. 11. As Table 2 shows, combining two hydrogen atoms on the stepped surface exhibits higher barrier and endothermic reaction energies of 1.28 and $0.81 \mathrm{eV}$ than on 

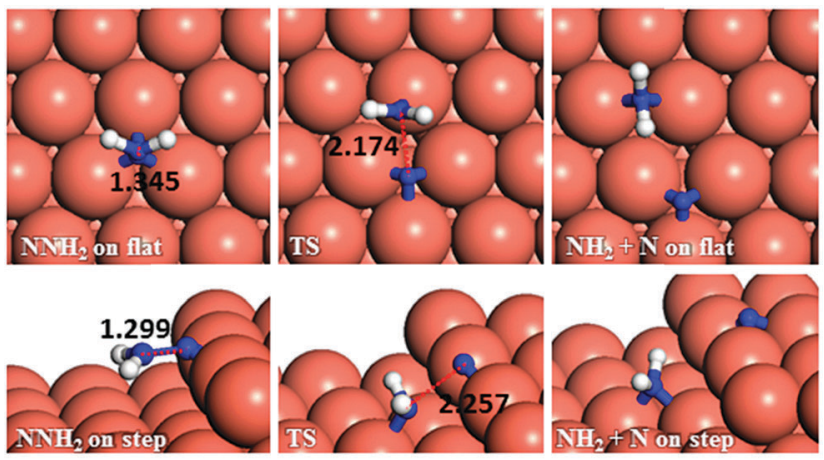

(a)
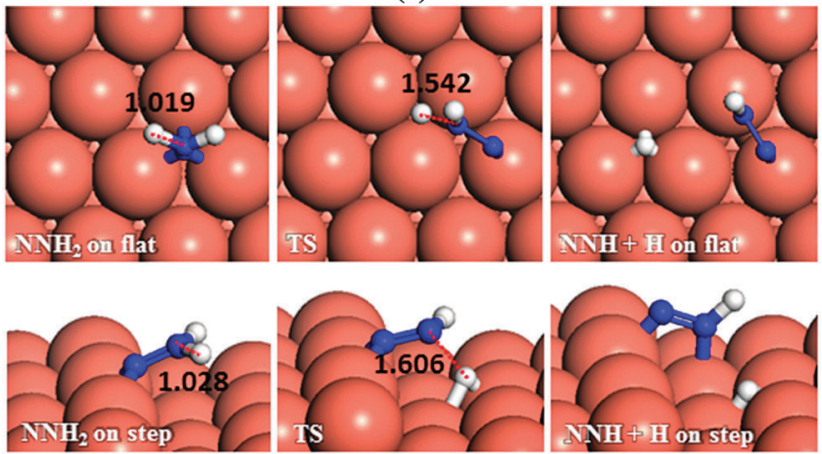

(b)

Fig. 6 Schematic representation of the initial, transition and final states for $\mathrm{NNH}_{2}$ dissociation pathways on the flat (top-view) and stepped (sideview) $\mathrm{Cu}(111)$ surfaces via (a) $\mathrm{N}-\mathrm{N}$, and (b) $\mathrm{N}-\mathrm{H}$ breaking. Bond lengths are given in $\AA$
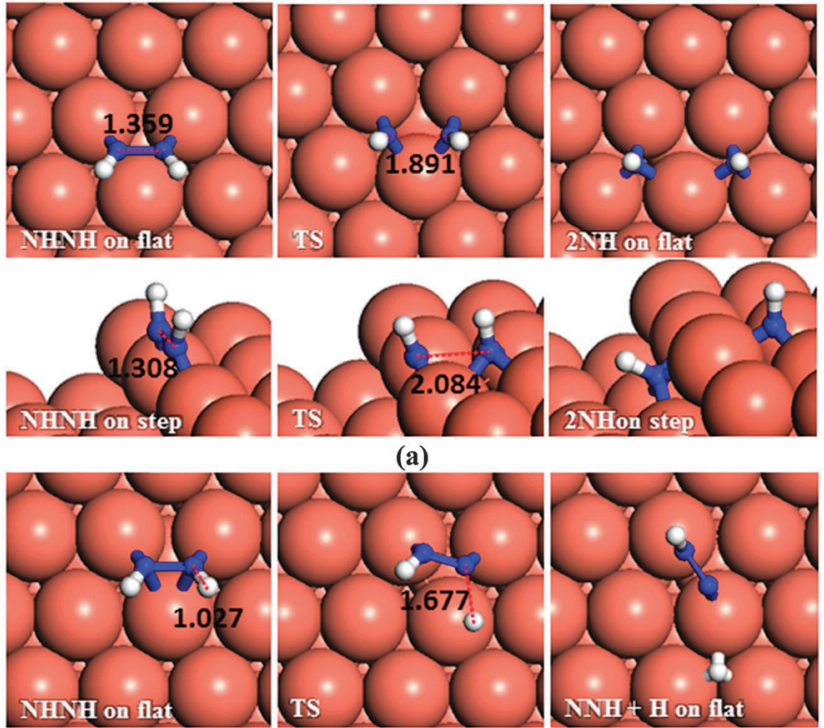

(a)
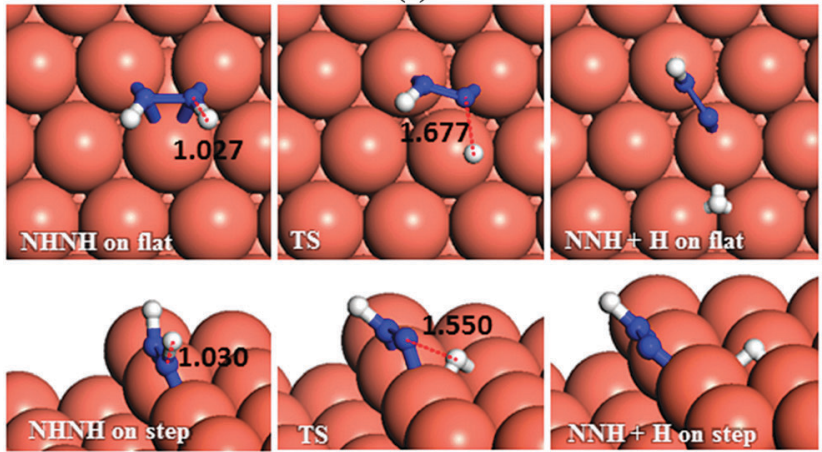

(b)

Fig. 7 Schematic representation of the initial, transition and final states for $\mathrm{NHNH}$ dissociation pathways on the flat (top-view) and stepped (side-view) $\mathrm{Cu}(111)$ surfaces via (a) $\mathrm{N}-\mathrm{N}$, and (b) $\mathrm{N}-\mathrm{H}$ breaking. Bond lengths are given in $\AA$.
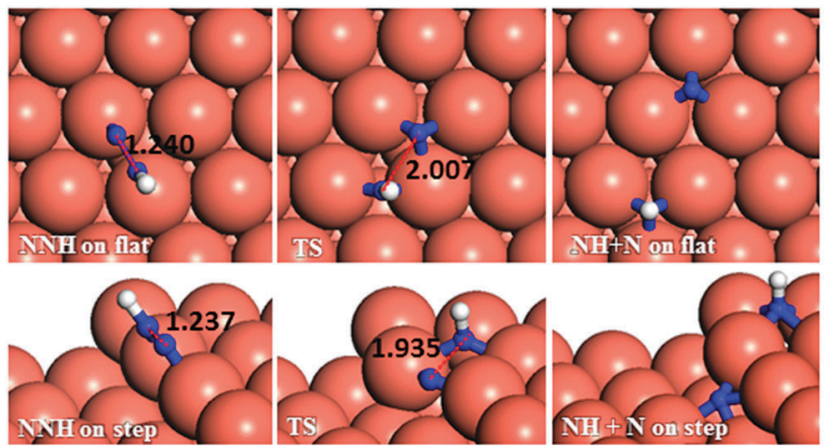

(a)
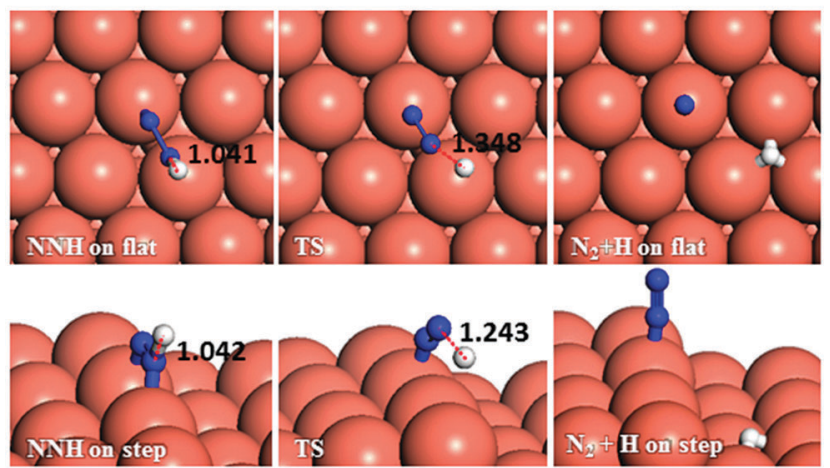

(b)

Fig. 8 Schematic representation of the initial, transition and final states for $\mathrm{NNH}$ dissociation pathways on the flat (top-view) and stepped (side-view) $\mathrm{Cu}(111)$ surfaces via (a) $\mathrm{N}-\mathrm{N}$, (b) $\mathrm{N}-\mathrm{H}$ breaking. Bond lengths are given in $\AA$.
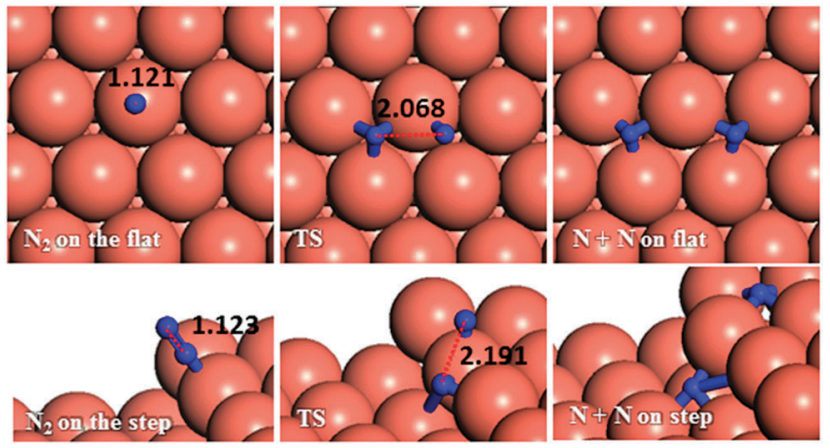

Fig. 9 Schematic representation of the initial, transition and final states for $\mathrm{N}_{2}$ dissociation pathways on the flat (top-view) and stepped (side-view) $\mathrm{Cu}(111)$ surfaces. Bond lengths are given in $\AA$.

the flat surface, $E_{\mathrm{a}}=1.08$ and $E_{\mathrm{r}}=0.43 \mathrm{eV}$. The reverse reaction, the exothermic $\mathrm{H}_{2}$ dissociation reaction, has energy barriers of 0.65 and $0.47 \mathrm{eV}$ on the terrace and stepped surfaces, respectively, indicating that $\mathrm{H}_{2}$ should adsorb dissociatively on $\mathrm{Cu}$ surfaces and the presence of a step edge makes this process more likely to proceed, due to the stabilisation provided by the low-coordinated atoms, where the electronic structure is different than that for the terrace atoms. ${ }^{27,28}$

\subsection{Intermolecular dehydrogenation pathways}

Having investigated the barriers for both $\mathrm{N}-\mathrm{N}$ and $\mathrm{N}-\mathrm{H}$ bond scission of the different possible intermediates of $\mathrm{N}_{2} \mathrm{H}_{4}$ 


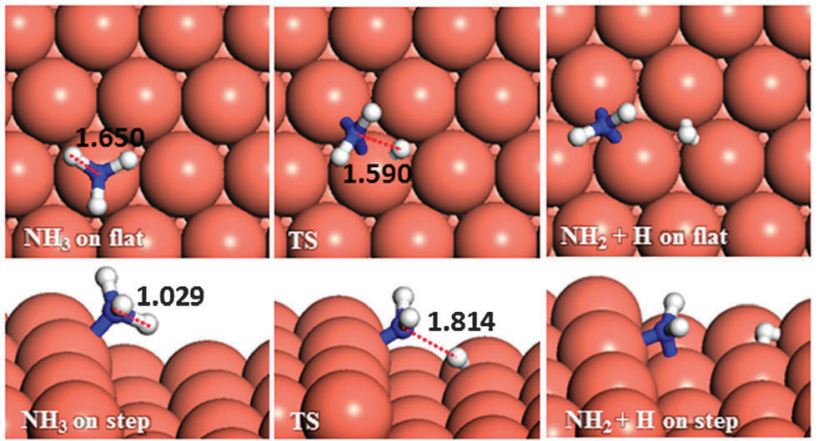

(a)
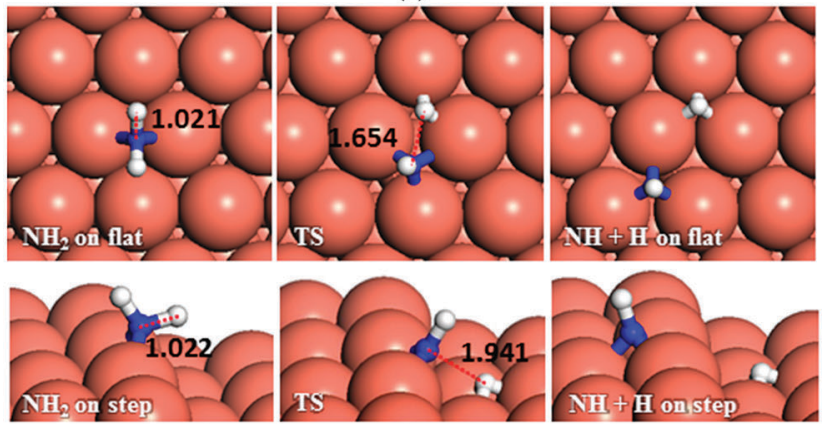

(b)
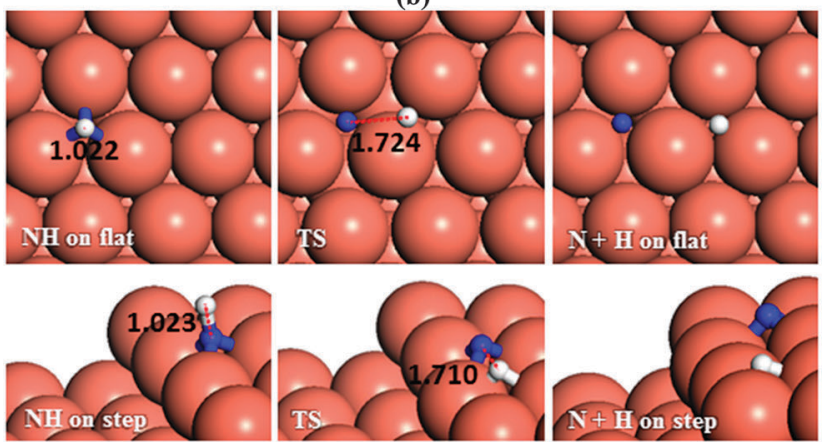

(c)

Fig. 10 Schematic representation of the initial, transition and final states for (a) $\mathrm{NH}_{3}$, (b) $\mathrm{NH}_{2}$ and (c) $\mathrm{NH}$ dehydrogenation pathways on the flat (top-view) and stepped (side-view) Cu(111) surfaces. Bond lengths are given in $\AA$.

dissociation, it is evident that breaking the hydrazine $\mathrm{N}-\mathrm{N}$ bond and producing $\mathrm{NH}_{2}$ fragments is the most likely process to occur on both the flat and stepped $\mathrm{Cu}(111)$ surfaces. Furthermore, the dehydrogenation of $\mathrm{NH}_{2}$ is unfavourable to proceed at low temperatures due to the high energy of the transition states. We have therefore investigated other pathways involving the $\mathrm{NH}_{2}$ groups. There are two possibilities: $\mathrm{NH}_{2}$ can either react with another $\mathrm{N}_{2} \mathrm{H}_{x}(x=1-4)$ intermediate and subtract a hydrogen, or react with another $\mathrm{NH}_{2}$ from hydrazine decomposition.

3.5.1 $\mathbf{N}_{2} \mathbf{H}_{x}(x=1-4)$ dehydrogenation by $\mathbf{N H}_{2}$. The intermediate $\mathrm{NH}_{2}$ may interact with hydrazine or other decomposition intermediates, and the pathways for subsequent dehydrogenation steps are shown in Fig. 12.

In the first suggested process (Fig. 12a), $\mathrm{NH}_{2}$ interacts with $\mathrm{N}_{2} \mathrm{H}_{4}$ and abstracts one of its $\mathrm{H}$ atoms leading to $\mathrm{N}_{2} \mathrm{H}_{3}$ and $\mathrm{NH}_{3}$. The energy barrier for this process is $0.59 \mathrm{eV}$ on the flat surface, but it decreases to only $0.03 \mathrm{eV}$ on the stepped surface,

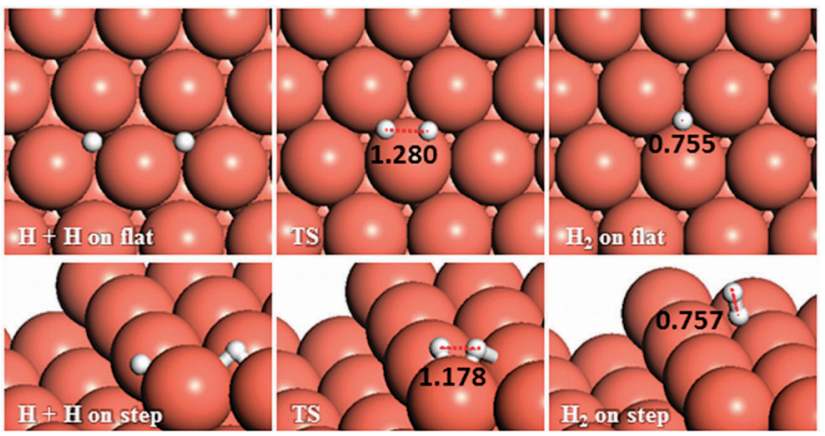

Fig. 11 Schematic representation of the initial, transition and final states for $\mathrm{H}-\mathrm{H}$ coupling pathways on the flat (top-view) and stepped (side-view) $\mathrm{Cu}(111)$ surfaces. Bond lengths are given in $\AA$.

and releases energies of 0.35 and $0.22 \mathrm{eV}$, respectively. This step therefore could proceed fairly easily on both the flat and stepped $\mathrm{Cu}(111)$ surfaces.

In the second process, represented in Fig. $12 \mathrm{~b}$ and $\mathrm{c}$, the $\mathrm{NH}_{2}$ molecule subtracts a hydrogen from $\mathrm{N}_{2} \mathrm{H}_{3}$ leading to $\mathrm{NNH}_{2}$ or $\mathrm{NHNH}$. If $\mathrm{NNH}_{2}$ is formed, the process requires overcoming a barrier of $0.70 \mathrm{eV}$, but the products are $0.12 \mathrm{eV}$ more favourable than the reactants on the flat surface. The presence of steps on the surface leads to $\mathrm{NNH}_{2}$ via a slightly lower barrier $\left(E_{\mathrm{a}}=\right.$ $0.67 \mathrm{eV}$ ), but releasing only $0.06 \mathrm{eV}$. The alternative pathway, leading to $\mathrm{NHNH}$, has barriers of 0.80 and $0.64 \mathrm{eV}$ on the terrace and step, respectively, while the process is endothermic by $0.11 \mathrm{eV}$ on the terrace and practically in thermodynamic equilibrium $\left(E_{\mathrm{r}}=-0.01 \mathrm{eV}\right)$ on the stepped surface.

In the next dehydrogenation pathway (Fig. 12d and e), $\mathrm{NH}_{2}$ reacts with either the $\mathrm{NNH}_{2}$ or $\mathrm{NHNH}$ structure, leading to the formation of NNH. The dehydrogenation process starting with $\mathrm{NNH}_{2}$ is endothermic by $0.15 \mathrm{eV}$ with an energy barrier of $0.44 \mathrm{eV}$ on the terrace, while on the stepped surface it has a barrier of only $0.15 \mathrm{eV}$ and an exothermic reaction energy of $0.47 \mathrm{eV}$. However, the interaction between $\mathrm{NHNH}$ and $\mathrm{NH}_{2}$ is exothermic by 0.26 with a barrier of only $0.36 \mathrm{eV}$ on the flat surface which increases by $0.64 \mathrm{eV}$ for a thermodynamically equilibrated reaction on the stepped surface $\left(E_{\mathrm{a}}=1.00\right.$ and $\left.E_{\mathrm{r}}=0.01 \mathrm{eV}\right)$. The reaction between $\mathrm{NH}_{2}$ and $\mathrm{NHNH}$ is therefore likely to succeed on the flat surface, although the reaction between $\mathrm{NNH}_{2}$ and $\mathrm{NH}_{2}$ is more feasible on the stepped surface.

In the last dehydrogenation process, the reaction between $\mathrm{NH}_{2}$ and $\mathrm{NNH}$ yields $\mathrm{N}_{2}$ and $\mathrm{NH}_{3}$ (Fig. 12f). This reaction is highly exothermic releasing energies of 2.13 and $1.60 \mathrm{eV}$ on the flat and stepped surfaces, respectively, which may be used for the desorption of $\mathrm{N}_{2}$ and $\mathrm{NH}_{3}$, which requires energies of 0.15 and $0.81 \mathrm{eV}$ on the flat and 0.39 and $1.06 \mathrm{eV}$ on the stepped surfaces, respectively.

3.5.2 Interaction of $\mathrm{NH}_{2}$ molecules. The $\mathrm{NH}_{2}$ molecules, i.e. produced by hydrazine $\mathrm{N}-\mathrm{N}$ bond scission, may also react together leading to $\mathrm{NH}$ and $\mathrm{NH}_{3}$, see Fig. 13. The calculated energy barrier for this reaction is only $0.55 \mathrm{eV}$ and the products are practically in thermodynamic equilibrium with the reactants $\left(E_{\mathrm{r}}=-0.05 \mathrm{eV}\right)$ on the flat surface. Although this process is therefore feasible on the flat $\mathrm{Cu}(111)$ surface, it is rather 

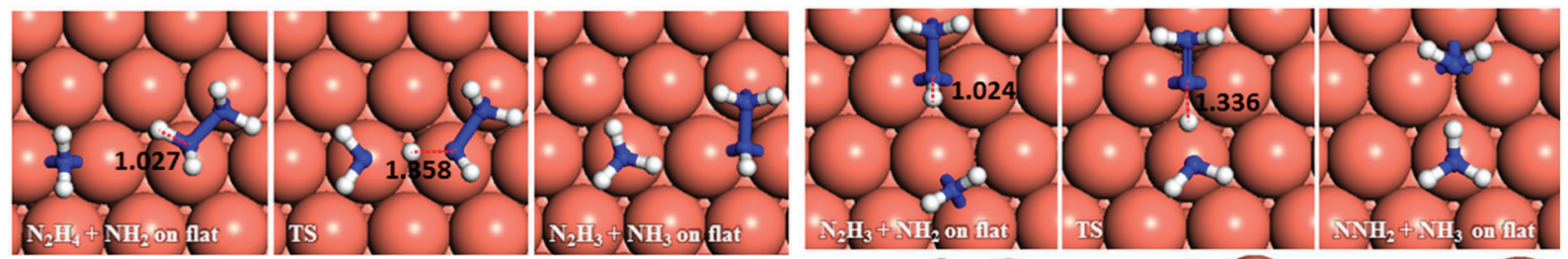

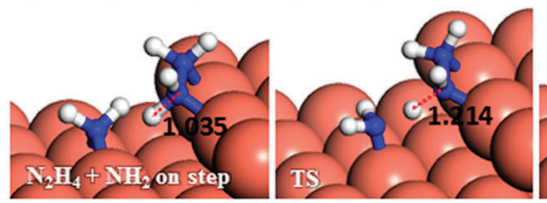

(a)

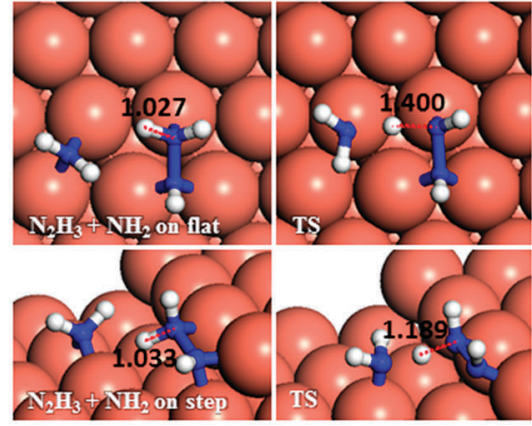

(c)
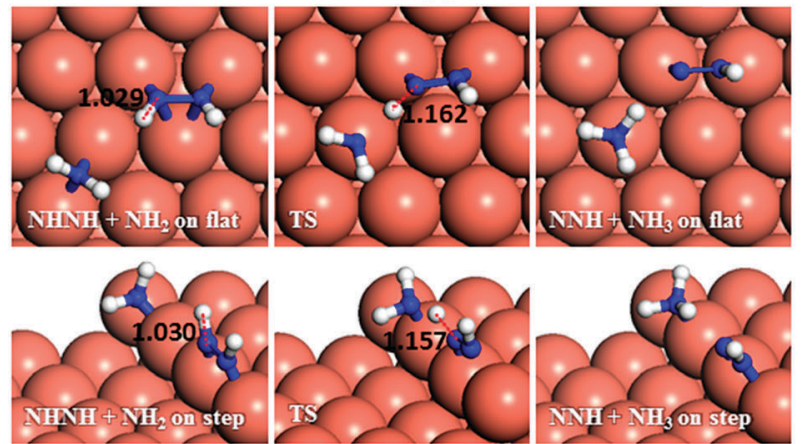

(e)
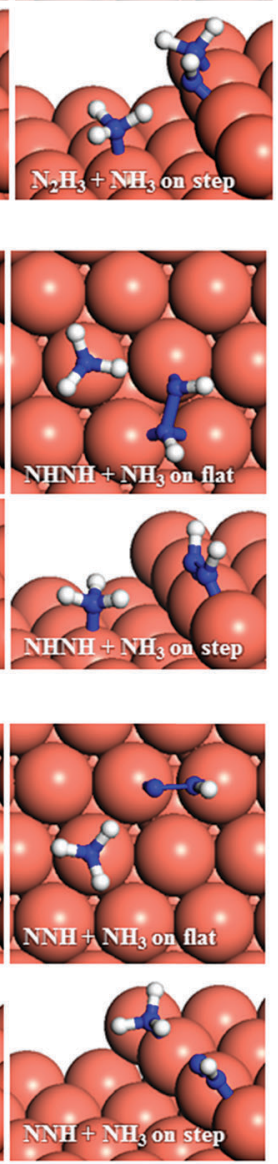

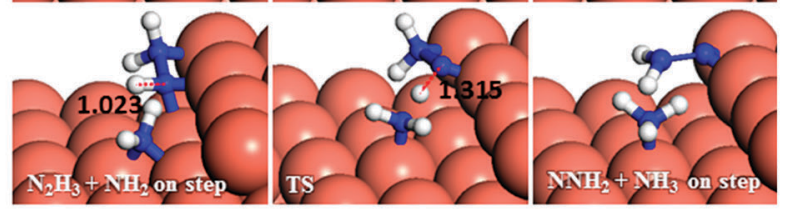

(b)

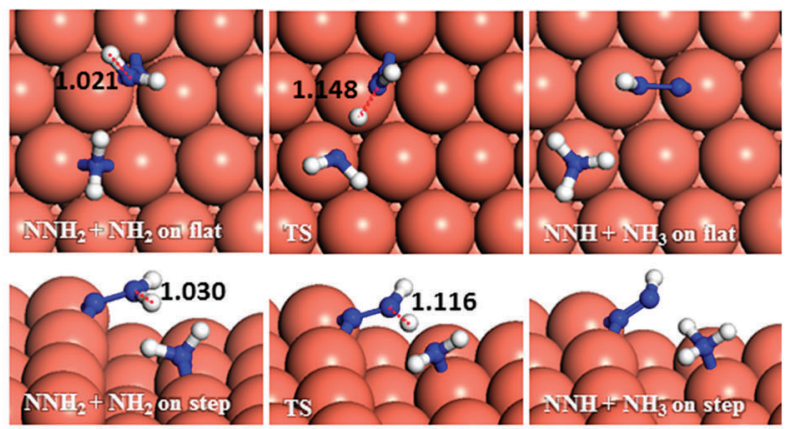

(d)
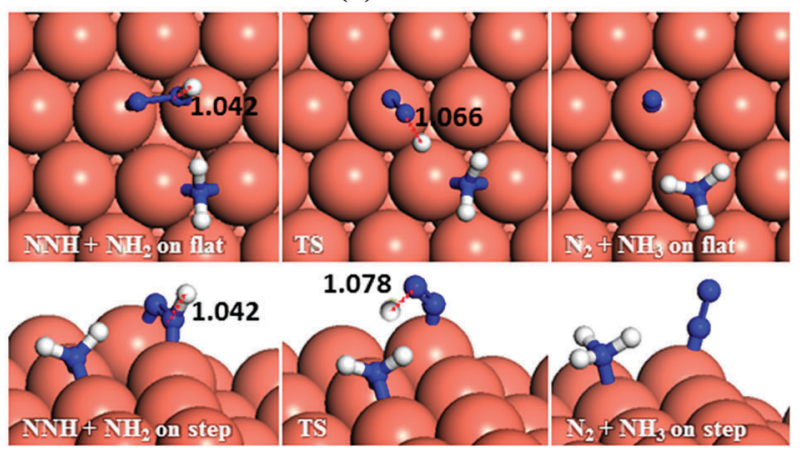

(f)

Fig. 12 Schematic representation of the initial, transition and final states for dehydrogenation pathways on the flat (top-view) and stepped (side-view) $\mathrm{Cu}$ (111) via $\mathrm{NH}_{2}$ attacking to (a) $\mathrm{N}_{2} \mathrm{H}_{4}$, (b) and (c) $\mathrm{N}_{2} \mathrm{H}_{3}$, (d) $\mathrm{NNH}_{2}$, (e) $\mathrm{NHNH}$ and (f) $\mathrm{NNH}$. Bond lengths are given in $\AA$.
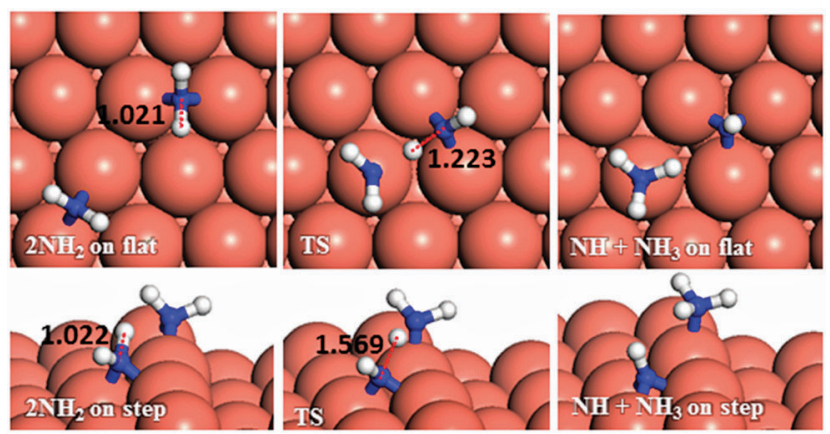

Fig. 13 Schematic representation of the initial, transition and final states for dehydrogenation pathways via $\mathrm{NH}_{2}$ attacking $\mathrm{NH}_{2}$ on the flat (top-view) and stepped (side-view) $\mathrm{Cu}(111)$ surfaces. Bond lengths are given in $\AA$.

difficult to succeed on the stepped surface, due to a high barrier energy of $2.05 \mathrm{eV}\left(E_{\mathrm{r}}=0.37 \mathrm{eV}\right)$.

\section{Discussion}

The most stable adsorption structures of the dehydrogenation intermediates showed that their order of stability on the surface with respect to hydrazine is $\mathrm{N}_{2} \mathrm{H}_{4}>\mathrm{N}_{2} \mathrm{H}_{3}>\mathrm{N}_{2} \mathrm{H}_{2}>\mathrm{N}_{2} \mathrm{H}$, indicating that more oxidised intermediates are less stable on the $\mathrm{Cu}$ surfaces. The same trend is found for the $\mathrm{N}-\mathrm{N}$ average bond lengths, showing that dehydrogenation results in a shorter and stronger $\mathrm{N}-\mathrm{N}$ bond and less stable intermediates on the surface.

We summarised the energy profiles of the reaction mechanism in Fig. 14-16. The plot in Fig. 14 contains the different pathways for intramolecular dehydrogenation, whereas the $\mathrm{N}_{2} \mathrm{H}_{4}$ decomposition via $\mathrm{N}-\mathrm{N}$ scission and further dehydrogenation reactions are shown in Fig. 15 and Fig. 16 summarises the intermolecular dehydrogenation pathway.

The $\mathrm{N}_{2} \mathrm{H}_{4}$ dehydrogenation, $\mathrm{N}_{2} \mathrm{H}_{4}{ }^{*} \rightarrow \mathrm{N}_{2} \mathrm{H}_{3}{ }^{*}+\mathrm{H}^{*}$, and subsequent ones are unlikely to occur under moderate conditions, 
owing to the high reaction barriers, see Table 2 and Fig. 14. The rate-determining step for the $\mathrm{N}_{2} \mathrm{H}_{4}$ intramolecular dehydrogenation mechanism is $\mathrm{NHNH}^{*} \rightarrow \mathrm{NNH}^{*}+\mathrm{H}^{*}$ on the flat surface with an energy barrier of $1.68 \mathrm{eV}$, and $\mathrm{N}_{2} \mathrm{H}_{3}{ }^{*} \rightarrow \mathrm{NNH}_{2}{ }^{*}+$ $\mathrm{H}^{*}$ on the stepped surface with an activation barrier of $1.77 \mathrm{eV}$. It is therefore unlikely that a large amount of $\mathrm{N}_{2}$ is produced via this intramolecular dehydrogenation pathway. Overall, from the investigation of $\mathrm{N}-\mathrm{H}$ bond scission of all species on the surface, $\mathrm{NNH}$ is the only fragment which is easily dehydrogenated to the
$\mathrm{N}_{2}$ molecule, with barriers of only 0.37 and $0.62 \mathrm{eV}$ on the flat and stepped surfaces, respectively, and a relatively exothermic reaction $\left(E_{\mathrm{r}} \sim 1.3 \mathrm{eV}\right)$. These results also suggest that at moderate temperatures the recombination of produced $\mathrm{H}$ atoms will lead to the formation of $\mathrm{H}_{2}$; this reaction has activation energies of $\sim 1.1 \mathrm{eV}$ on the flat and stepped surfaces and the products desorb easily from the surface.

From investigation of $\mathrm{N}-\mathrm{N}$ bond scission in any intermediate on the surface, we found that the $\mathrm{N}-\mathrm{N}$ decoupling in

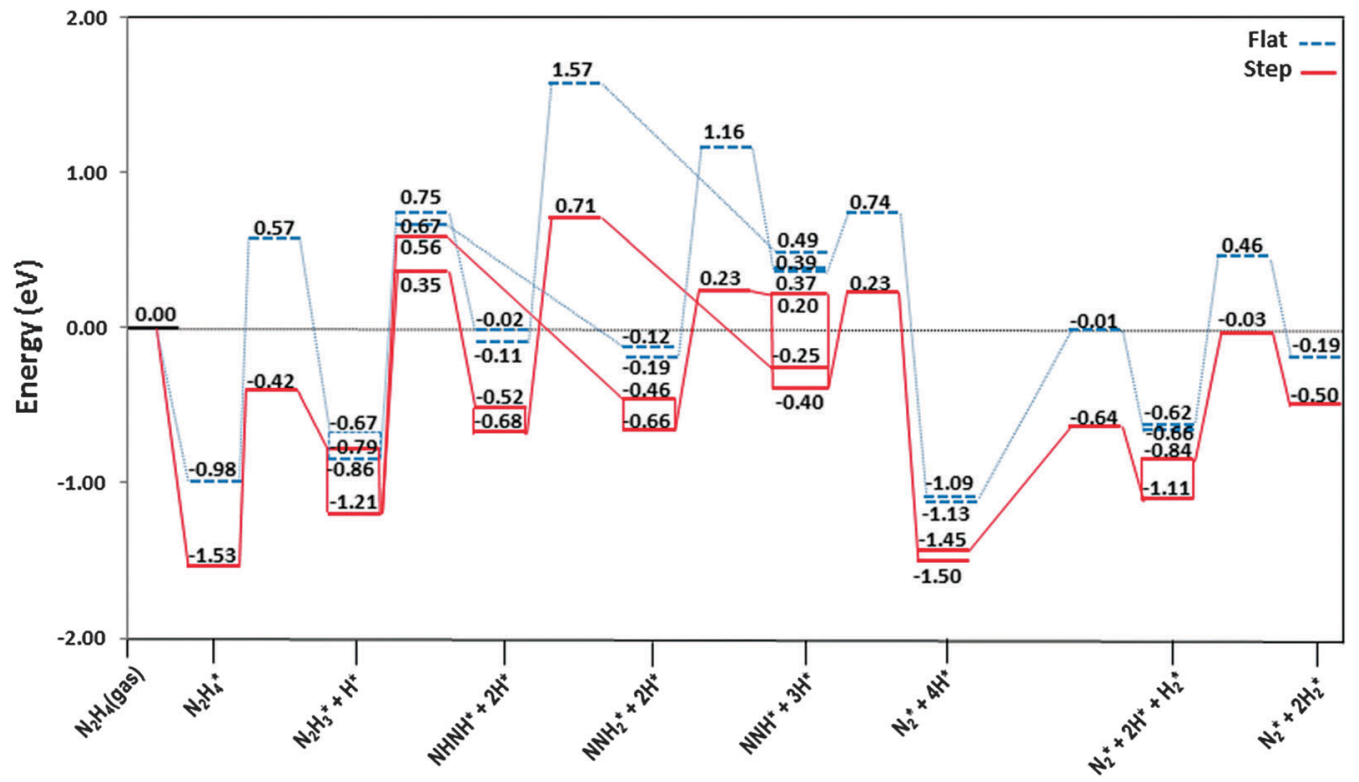

Fig. 14 Reaction profiles for dissociation of $\mathrm{N}_{2} \mathrm{H}_{4}$ via intramolecular dehydrogenation mechanism on the flat (---) and stepped (-) Cu(111) surfaces. Energies are relative to the energy of the gas-phase hydrazine (in eV). Note that we have considered the diffusion of intermediates to their most stable adsorption sites on the surface as a barrierless pathway.

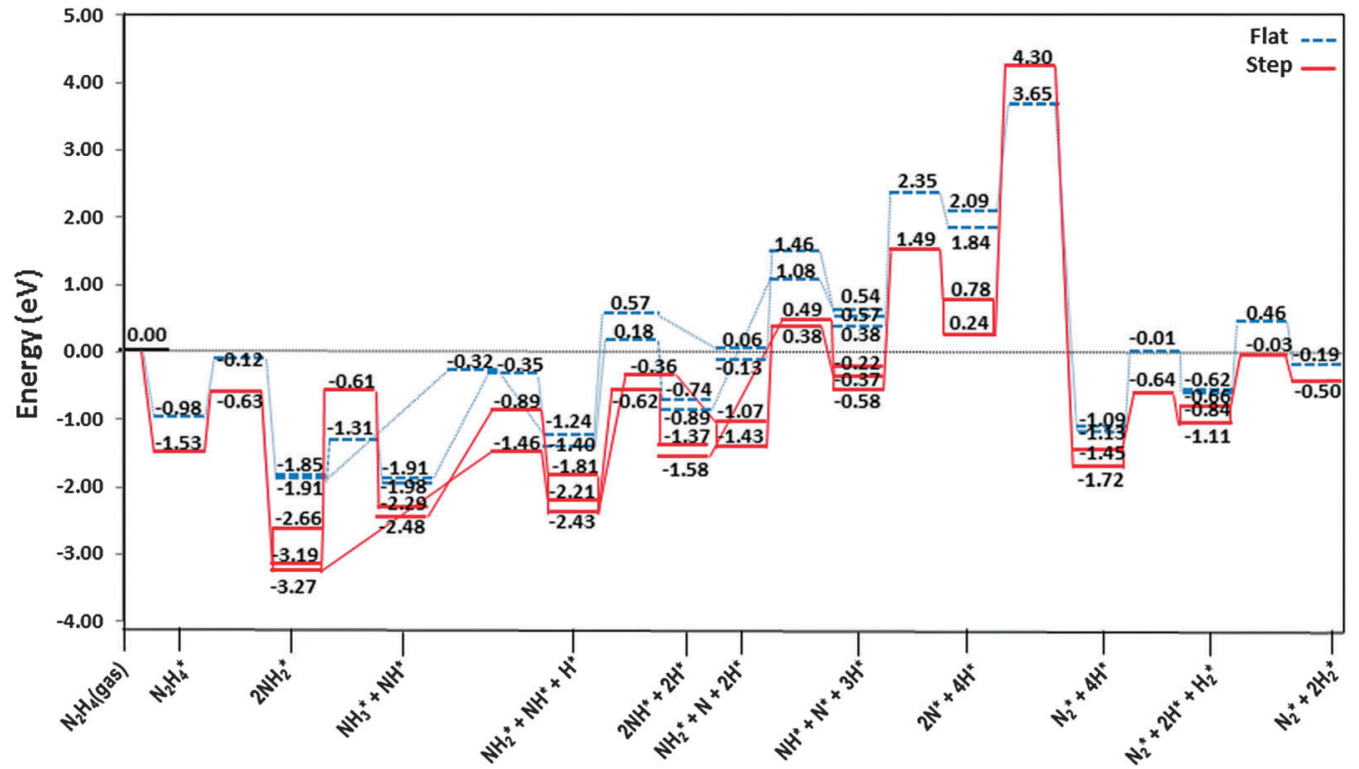

Fig. 15 Reaction profiles for dissociation of $\mathrm{N}_{2} \mathrm{H}_{4}$ via $\mathrm{N}-\mathrm{N}$ bond breaking and subsequent dehydrogenation pathways on the flat (-- -) and stepped (-) $\mathrm{Cu}(111)$ surfaces. Energies are relative to the energy of the gas-phase hydrazine (in eV). Note that we have considered the diffusion of intermediates to their most stable adsorption sites on the surface as a barrierless pathway. 


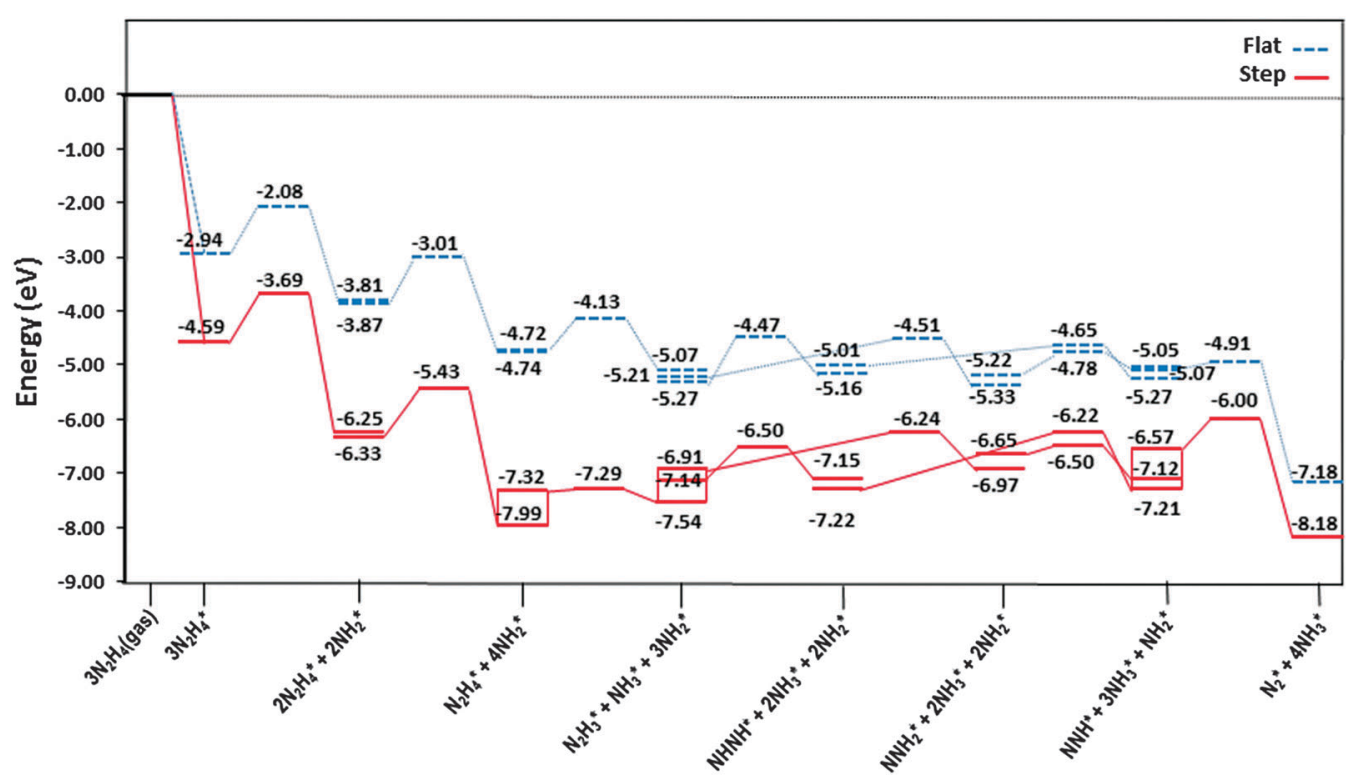

Fig. 16 Reaction profiles for dissociation of $\mathrm{N}_{2} \mathrm{H}_{4}$ via intermolecular dehydrogenation via $\mathrm{NH}_{2}$ on the flat (---) and stepped (-) Cu(111) surfaces. Energies are relative to the energy of the gas-phase hydrazine (in eV). Note that we have considered the diffusion of intermediates to their most stable adsorption sites on the surface as a barrierless pathway.

$\mathrm{N}_{2} \mathrm{H}_{4}\left(\mathrm{~N}_{2} \mathrm{H}_{4}{ }^{*} \rightarrow 2 \mathrm{NH}_{2}^{*}\right)$, see Table 2 and Fig. 15, is the predominant mechanism, leading to amide intermediate production in agreement with experiment. ${ }^{59}$ The exothermic decomposition of $\mathrm{N}_{2} \mathrm{H}_{3}$ and $\mathrm{NHNH}$ fragments via $\mathrm{N}-\mathrm{N}$ decoupling also has low activation energies compared to the other intermediates on the flat and stepped surfaces.

The production of $\mathrm{NH}_{3}$ takes place from the exothermic reaction of $\mathrm{NH}_{2}$ radicals on the flat surface by an activation energy of only $0.55 \mathrm{eV}$. Further $\mathrm{NH}_{3}$ production from the interaction of $\mathrm{N}_{2} \mathrm{H}_{x}(x=1-4)$ and $\mathrm{NH}_{2}$ is also possible, resulting in the production of $\mathrm{N}_{2}$; all these steps have barrier energies below $1 \mathrm{eV}$ on either the flat or stepped surfaces, see Table 2 and Fig. 16. The rate-determining step for the intermolecular dehydrogenation via $\mathrm{NH}_{2}$ is the reaction $\mathrm{N}_{2} \mathrm{H}_{3}{ }^{*}+\mathrm{NH}_{2}{ }^{*} \rightarrow$ $\mathrm{NHNH}^{*}+\mathrm{NH}_{3}{ }^{*}$ which has an activation energy of $0.80 \mathrm{eV}$ on the flat surface, while on the stepped surfaces $\mathrm{NHNH}^{*}+\mathrm{NH}_{2}{ }^{*} \rightarrow$ $\mathrm{NNH}^{*}+\mathrm{NH}_{3}^{*}$ has a barrier of $1.00 \mathrm{eV}$ where it is the ratedetermining step. The $\mathrm{N}_{2}$ molecule produced from one single hydrazine molecule via an intermolecular dehydrogenation mechanism, Fig. 16, is in agreement with experimental reports where $\mathrm{N}_{2} \mathrm{H}_{4}$ remains stable during the dissociation process. ${ }^{59,63}$

Thus we may conclude that the $\mathrm{NH}_{2}$ radical governs the $\mathrm{N}_{2} \mathrm{H}_{4}$ dissociation, which agrees well with experimental studies about the role of $\mathrm{NH}_{2}$ in the hydrazine decomposition. ${ }^{64,65}$ The released energies from the exothermic reactions provide enough energy for the evolution of $\mathrm{NH}_{3}, \mathrm{~N}_{2}$ and $\mathrm{H}_{2}$ gases from the surface. Experimental studies also revealed that the decomposition of hydrazine on copper films occurs above $300 \mathrm{~K}$ with gaseous products of $\mathrm{NH}_{3}, \mathrm{~N}_{2}$ and some $\mathrm{H}_{2},{ }^{10}$ which is consistent with the mechanism in Fig. 16.

Furthermore, the calculations showed the influence of lowcoordinated atoms on the different $\mathrm{N}_{2} \mathrm{H}_{4}$ decomposition pathways, i.e. at the step edges. These surface atoms stabilise some intermediates more than others along the different pathways, although there is no clear trend in the activation energies except to increase the $\mathrm{N}-\mathrm{N}$ decoupling barriers of the intermediates in the presence of step edge atoms.

\section{Conclusions}

We have employed DFT level calculations with long-range interaction corrections to carry out a systematic study of the $\mathrm{N}_{2} \mathrm{H}_{4}$ decomposition mechanisms on the flat and stepped $\mathrm{Cu}(111)$ surfaces. We have identified the most stable adsorption sites for all intermediates along the different mechanisms of $\mathrm{N}-\mathrm{H}$ and $\mathrm{N}-\mathrm{N}$ bond scission. We have found that $\mathrm{N}_{2} \mathrm{H}_{4}$ dehydrogenation is kinetically an unlikely process on both flat and stepped $\mathrm{Cu}(111)$ surfaces due to high barrier energies. However, $\mathrm{N}-\mathrm{N}$ decoupling is energetically feasible, leading to $\mathrm{NH}_{2}$ intermediates. The intermolecular dehydrogenation reaction is the predominant mechanism between either $\mathrm{NH}_{2}$ fragments on the flat surface, or $\mathrm{NH}_{2}$ and $\mathrm{N}_{2} \mathrm{H}_{x}(x=1-4)$ intermediates on the flat or stepped surfaces, leading to the formation of $\mathrm{N}_{2}$ and $\mathrm{NH}_{3}$, as shown in Fig. 16. This process is highly exothermic, releasing $\sim 2.50 \mathrm{eV}$ per hydrazine molecule, which agrees well with the use of $\mathrm{N}_{2} \mathrm{H}_{4}$ as a rocket fuel. Meanwhile the amide and imide intermediates are hydrogenated to $\mathrm{NH}_{3}$ in the presence of hydrogen, which competes with the recombination of $\mathrm{H}$ atoms leading to $\mathrm{H}_{2}$ molecules. We also found that, while the introduction of lowcoordinated atoms, as on the step edge on the surface, increases the barrier of $\mathrm{N}-\mathrm{N}$ decoupling along the reaction, it has different effects on the barriers of intra- and intermolecular dehydrogenation mechanisms.

Future work will include microkinetic simulations to develop our understanding of the competing catalytic processes leading to $\mathrm{N}_{2} \mathrm{H}_{4}$ dissociation on the planar $\mathrm{Cu}(111)$ surfaces. 


\section{Acknowledgements}

S.S.T acknowledges University College London and the UCL Industrial Doctorate Centre in Molecular Modelling and Materials Science for an Overseas Research Scholarship. N.H.d.L acknowledges the Royal Society for an Industry Fellowship and A.R. is grateful to the Ramsay Memorial Trust and University College London for the award of a Ramsay Fellowship. Via our membership of the UK's HPC Materials Chemistry Consortium, which is funded by EPSRC (EP/L000202), this work made use of the facilities of HECTOR and ARCHER, the UK's national highperformance computing service, which is funded by the Office of Science and Technology through EPSRC's High End Computing Programme, as well as the UCL Legion High Performance Computing facility (Legion@UCL), and associated support services, in the completion of this work.

\section{References}

1 S. Dutta, J. Ind. Eng. Chem., 2014, 20, 1148-1156.

2 L. Schlapbach and A. Zuttel, Nature, 2001, 414, 353-358.

3 M. Y. Zheng, R. H. Cheng, X. W. Chen, N. Li, L. Li, X. D. Wang and T. Zhang, Int. J. Hydrogen Energy, 2005, 30, 1081-1089.

4 E. W. Schmidt, Hydrazine and Its Deratives: Preparation, Properties, Applications, Wiley, New York, 2001.

5 S. G. Pakdehi, M. Salimi and M. Rasoolzadeh, Researches and Applications in Mechanical Engineering, 2014, 3, 21-25.

6 S. Mary, C. Kappenstein, S. Balcon, S. Rossignol and E. Gengembre, Appl. Catal., A, 1999, 182, 317-325.

7 S. Balcon, S. Mary, C. Kappenstein and E. Gengembre, Appl. Catal., A, 2000, 196, 179-190.

8 J. P. Contour and G. Pannetie, J. Catal., 1972, 24, 434-445.

9 M. H. Matloob and M. W. Roberts, J. Chem. Soc., Faraday Trans. 1, 1977, 73, 1393-1405.

10 Y. K. Alhaydari, J. M. Saleh and M. H. Matloob, J. Phys. Chem., 1985, 89, 3286-3290.

11 P. X. Zhang, Y. G. Wang, Y. Q. Huang, T. Zhang, G. S. Wu and J. Li, Catal. Today, 2011, 165, 80-88.

12 H. L. McKay, S. J. Jenkins and D. J. Wales, J. Phys. Chem. C, 2011, 115, 17812-17828.

13 T. D. Daff and N. H. de Leeuw, J. Mater. Chem., 2012, 22, 23210-23220.

14 J. K. Norskov, T. Bligaard, A. Logadottir, S. Bahn, L. B. Hansen, M. Bollinger, H. Bengaard, B. Hammer, Z. Sljivancanin, M. Mavrikakis, Y. Xu, S. Dahl and C. J. H. Jacobsen, J. Catal., 2002, 209, 275-278.

15 Z. P. Liu and P. Hu, J. Am. Chem. Soc., 2003, 125, 1958-1967.

16 T. Zubkov, G. A. Morgan, J. T. Yates, O. Kuhlert, M. Lisowski, R. Schillinger, D. Fick and H. J. Jansch, Surf. Sci., 2003, 526, 57-71.

17 P. Gambardella, Ž. Šljivančanin, B. Hammer, M. Blanc, K. Kuhnke and K. Kern, Phys. Rev. Lett., 2001, 87, 056103.

18 I. M. Ciobica and R. A. van Santen, J. Phys. Chem. B, 2002, 106, 6200-6205.
19 N. H. de Leeuw and J. A. Purton, Phys. Rev. B: Condens. Matter Mater. Phys., 2001, 63, 195417.

20 S. C. Parker, N. H. de Leeuw, D. J. Harris, F. M. Higgins, P. M. Oliver, S. E. Redfern and G. W. Watson, Radiat. Eff. Defects Solids, 1999, 151, 185-195.

21 S. Dahl, A. Logadottir, R. C. Egeberg, J. H. Larsen, I. Chorkendorff, E. Tornqvist and J. K. Norskov, Phys. Rev. Lett., 1999, 83, 1814-1817.

22 T. Zambelli, J. Wintterlin, J. Trost and G. Ertl, Science, 1996, 273, 1688-1690.

23 Y. Xu and M. Mavrikakis, J. Phys. Chem. B, 2003, 107, 9298-9307.

24 Y. Xu and M. Mavrikakis, Surf. Sci., 2003, 538, 219-232.

25 T. Li, B. Bhatia and D. S. Sholl, J. Chem. Phys., 2004, 121, 10241-10249.

26 S. S. Fu and G. A. Somorjai, Surf. Sci., 1992, 262, 68-76.

27 S. S. Tafreshi, A. Roldan, N. Y. Dzade and N. H. de Leeuw, Surf. Sci., 2014, 622, 1-8.

28 S. S. Tafreshi, A. Roldan and N. H. de Leeuw, J. Phys. Chem. C, 2014, 118, 26103-26114.

29 S. S. Tafreshi, A. Roldan and N. H. de Leeuw, Surf. Sci., 2015, 637-638, 140-148.

30 S. Grimme, J. Comput. Chem., 2004, 25, 1463-1473.

31 S. Grimme, J. Comput. Chem., 2006, 27, 1787-1799.

32 G. Kresse and J. Furthmuller, Phys. Rev. B: Condens. Matter Mater. Phys., 1996, 54, 11169-11186.

33 G. Kresse and J. Furthmuller, Comput. Mater. Sci., 1996, 6, 15-50.

34 G. Kresse and J. Hafner, Phys. Rev. B: Condens. Matter Mater. Phys., 1993, 47, 558-561.

35 G. Kresse and J. Hafner, Phys. Rev. B: Condens. Matter Mater. Phys., 1994, 49, 14251-14269.

36 J. P. Perdew, K. Burke and M. Ernzerhof, Phys. Rev. Lett., 1996, 77, 3865-3868.

37 G. Kresse and D. Joubert, Phys. Rev. B: Condens. Matter Mater. Phys., 1999, 59, 1758-1775.

38 P. E. Blochl, Phys. Rev. B: Condens. Matter Mater. Phys., 1994, 50, 17953-17979.

39 S. Irrera, A. Roldan, G. Portalone and N. H. De Leeuw, J. Phys. Chem. C, 2013, 117, 3949-3957.

40 N. Y. Dzade, A. Roldan and N. H. de Leeuw, J. Chem. Phys., 2013, 139, 124708.

41 N. Almora-Barrios, G. Carchini, P. Blonski and N. Lopez, J. Chem. Theory Comput., 2014, 10, 5002-5009.

42 W. Reckien, F. Janetzko, M. F. Peintinger and T. Bredow, J. Comput. Chem., 2012, 33, 2023-2031.

43 H. J. Monkhorst and J. D. Pack, Phys. Rev. B: Solid State, 1976, 13, 5188-5192.

44 R. Koitz, A. P. Seitsonen, M. Iannuzzi and J. Hutter, Nanoscale, 2013, 5, 5589-5595.

45 M. Gajdos and J. Hafner, Surf. Sci., 2005, 590, 117-126.

46 G. Mills and H. Jonsson, Phys. Rev. Lett., 1994, 72, 1124-1127.

47 G. Mills, H. Jonsson and G. K. Schenter, Surf. Sci., 1995, 324, 305-337.

48 A. Heyden, A. T. Bell and F. J. Keil, J. Chem. Phys., 2005, 123, 224101. 
49 T. D. Daff, D. Costa, I. Lisiecki and N. H. de Leeuw, J. Phys. Chem. C, 2009, 113, 15714-15722.

50 N. H. de Leeuw, S. C. Parker, C. R. A. Catlow and G. D. Price, Am. Mineral., 2000, 85, 1143-1154.

51 N. H. de Leeuw and C. J. Nelson, J. Phys. Chem. B, 2003, 107, 3528-3534.

52 N. H. de Leeuw, C. J. Nelson, C. R. A. Catlow, P. Sautet and W. Dong, Phys. Rev. B: Condens. Matter Mater. Phys., 2004, 69, 045419.

53 J. A. Pople and L. A. Curtiss, J. Chem. Phys., 1991, 95, 4385-4388.

54 K. P. Huber and G. Herzberg, Molecular Spectra and Molecular Structure: IV. Constants of Diatomic Molecules, Van Nostrand Reinhold Company, New York, 1979.

55 G. C. Wang, L. Jiang, X. Y. Pang and J. Nakamura, J. Phys. Chem. B, 2005, 109, 17943-17950.
56 W. Biemolt, P. R. Davies, A. P. J. Jansen and R. A. Vansanten, Catal. Today, 1992, 12, 427-432.

57 W. Biemolt, G. J. C. S. Vandekerkhof, P. R. Davies, A. P. J. Jansen and R. A. Vansanten, Chem. Phys. Lett., 1992, 188, 477-486.

58 D. R. Lide, CRC Handbook of Cemistry and Physics, CRC Press, New York, 1996.

59 J. Block and G. Schulzek, J. Catal., 1973, 30, 327-329.

60 J. Gomez-Diaz and N. Lopez, J. Phys. Chem. C, 2011, 115, 5667-5674.

61 A. Logadottir and J. K. Norskov, J. Catal., 2003, 220, 273-279.

62 K. Honkala, A. Hellman, I. N. Remediakis, A. Logadottir, A. Carlsson, S. Dahl, C. H. Christensen and J. K. Norskov, Science, 2005, 307, 555-558.

63 R. Maurel and J. C. Menezo, J. Catal., 1978, 51, 293-295.

64 K. I. Aika, T. Ohhata and A. Ozaki, J. Catal., 1970, 19, 140.

65 A. A. Konnov and J. De Ruyck, Combust. Flame, 2001, 124, 106-126. 